ARTICLE

https://doi.org/10.1038/s41467-019-12243-0

\title{
Double negative T cells mediate Lag3-dependent antigen-specific protection in allergic asthma
}

Dan Tian (1) 1,2,3,4, Lu Yang 1,3,4, Song Wang 2,3,4, Yanbing Zhu'2,3,4, Wen Shi 2,3,4, Chunpan Zhang 2,3,4,

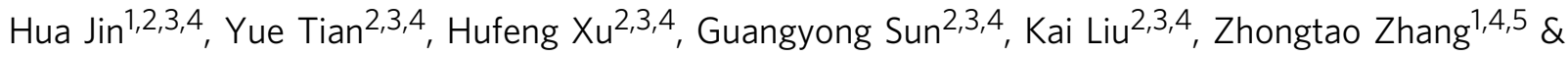
Dong Zhang (1) 1,2,3,4,5

\begin{abstract}
Allergic asthma is an inflammatory disorder of the airway without satisfactory traditional therapies capable of controlling the underlying pathology. New approaches that can overcome the detrimental effects of immune dysregulation are thus desirable. Here we adoptively transfer ovalbumin (OVA) peptide-primed $\mathrm{CD}^{-}{ }^{-} \mathrm{CD} 8^{-}$double negative $T$ (DNT) cells intravenously into a mouse model of OVA-induced allergic asthma to find that OVA-induced airway hyperresponsiveness, lung inflammation, mucus production and OVA-specific lgG/lgE production are significantly suppressed. The immunosuppressive function of the OVAspecific DNT cells is dependent on the inhibition of $\mathrm{CD}_{11 \mathrm{~b}}{ }^{+}$dendritic cell function, $\mathrm{T}$ follicular helper cell proliferation, and IL-21 production. Mechanistically, Lag3 contributes to MHC-II antigen recognition and trogocytosis, thereby modulating the antigen-specific immune regulation by DNT cells. The effectiveness of ex vivo-generated allergen-specific DNT cells in alleviating airway inflammation thus supports the potential utilization of DNT cell-based therapy for the treatment of allergic asthma.
\end{abstract}

\footnotetext{
${ }^{1}$ General Surgery Department, Beijing Friendship Hospital, Capital Medical University, Beijing 100050, China. ${ }^{2}$ Experimental and Translational Research Center, Beijing Friendship Hospital, Capital Medical University, Beijing 100050, China. ${ }^{3}$ Beijing Clinical Research Institute, Beijing 100050 , China. ${ }^{4}$ Beijing Key Laboratory of Tolerance Induction and Organ Protection in Transplantation, Beijing 100050, China. ${ }^{5}$ National Clinical Research Center for Digestive Diseases, Beijing 100050, China. Correspondence and requests for materials should be addressed to D.Z. (email: zhangd@ccmu.edu.cn)
} 
T he prevalence of allergic diseases and asthma is increasing worldwide, which is a major global challenge that threatens human health and economies. Moreover, the complexity and severity of allergic diseases, including asthma, continue to increase especially in children and young adults, who are bearing the greatest burden of these trends ${ }^{1,2}$. Allergic asthma is characterized by hyperresponsiveness, mucus production, inflammatory cell accumulation, and allergen-specific IgE secretion. The current most commonly used effective regimen is corticosteroid treatment, but patients often report unwanted long-term side effects ${ }^{3}$. The development of new approaches with better efficacy and fewer side effects is imperative to improving clinical treatment.

Th2 cells are considered to be the initial CD4 ${ }^{+} \mathrm{T}$ cells secreting pro-Th2 inflammatory cytokines in asthma ${ }^{4,5}$. This pathological response is prompted by allergen-presenting dendritic cells (DCs $)^{6,7}$. Moreover, a compelling number of reports have indicated that $\mathrm{T}$ follicular helper ( $\mathrm{Tfh}$ ) cells play an unexpected role in the pathogenesis of allergic asthma ${ }^{8,9}$. $\mathrm{T}$ cell subsets with regulatory functions have been discovered and applied to the treatment of autoimmune and allergic diseases ${ }^{10}$.

Double negative T cells (DNT cells) are unique antigen-specific regulatory $\mathrm{T}$ cells that express granzyme $\mathrm{B}$ and perforin but not Foxp3 and that were discovered in recent decades ${ }^{11,12}$. Although DNT cells only account for $1-3 \%$ of total T lymphocytes in the peripheral blood and lymphoid organs of humans and mice, these cells are essential for maintaining immune system homeostasis $^{13,14}$. Our previous studies demonstrated that CD4 ${ }^{+} \mathrm{T}$ cells are converted to DNT cells, which can significantly suppress $\mathrm{CD} 4{ }^{+} \mathrm{CD} 25^{-} \mathrm{T}$ cells, mainly through the perforin/granzyme $\mathrm{B}$ pathway ${ }^{15}$. The adoptive transfer of DNT cells can prevent and reverse the onset of autoimmune diabetes and prolong islet graft survival while preserving antigen specificity ${ }^{16,17}$. However, DNT cells lack the CD4 molecule, which is a critical coreceptor of the TCR that assists the TCR in interacting with MHC-II; the mechanism that allows DNT cells to recognize MHC-II and maintain antigen specificity is still unknown.

Here, we demonstrate that the adoptive transfer of DNT cells ameliorates ovalbumin (OVA)-induced airway hyperresponsiveness, lung inflammation, mucus production, inflammatory cell accumulation, and OVA-specific IgG/IgE production while preserving allergen specificity. We also provide evidence that lymphocyte-activation gene 3 (Lag3) is a key molecule that contributes to MHC-II antigen recognition and trogocytosis and thus affects the antigen-specific immune regulation of DNT cells.

\section{Results}

OVA DNTs prevented OVA-induced allergic airway inflammation. To investigate the therapeutic effects of OVA-primed DNT cells (OVA DNTs) in an OVA-induced allergic airway disease model, we adoptively transferred $2 \times 10^{6}$ OVA DNTs into OVA-sensitized mice intravenously after an initial challenge with 1\% OVA (Fig. 1a).

As illustrated in Fig. 1b, mice treated with OVA DNTs exhibited significantly reduced inflammatory cell infiltration of the lungs and mucus hypersecretion compared with nontreated mice. To investigate whether lung function was improved after the OVA DNT injection, we measured the Penh index of the mice after DNT cell treatment and OVA challenges. When exposed to high concentrations of methacholine $(50-100 \mathrm{mg} / \mathrm{ml})$, the Penh index was significantly lower in the OVA DNT-treated mice compared with the control mice $(P<0.001$, Fig. 1c).

Significantly decreased numbers of macrophages, lymphocytes, neutrophils, and eosinophils in bronchoalveolar lavage (BAL) fluid were found in OVA DNT-treated mice (Fig. 1d). Flow cytometry analysis also showed a decrease in the proportion and number of lung-infiltrating eosinophils in OVA DNT-treated mice $(P<0.001$, Fig. 1e, Supplementary Fig. 1A). Furthermore, the proportion of lung macrophages was significantly decreased after OVA DNT treatment $(P<0.05$, Supplementary Fig. 2A), while the proportions of lung lymphocytes and neutrophils were not changed (Supplementary Fig. $2 \mathrm{~B}$ and $1 \mathrm{C}$ ). These results demonstrated that DNT cells could restrict airway inflammation and ameliorate OVA-induced allergic asthma.

OVA DNTs infiltrated lungs and inhibited cytokine production. To trace the migration of OVA DNT cells in vivo, we generated MOG- or OVA-primed DNT cells from $\mathrm{GFP}^{+} \mathrm{CD} 4^{+}$ $\mathrm{T}$ cells. We intravenously injected the same number of $\mathrm{GFP}^{+}$ MOG or OVA DNT cells into mice with OVA-induced asthma and measured the accumulation of $\mathrm{GFP}^{+}$DNT cells in different tissues. Compared with MOG DNT cells, OVA DNTs were mainly accumulated in the lungs, BAL, spleen and mediastinal lymph node $(\mathrm{mLN})$ of mice $48 \mathrm{~h}$ after the last OVA challenge (Fig. 2a, b). These data suggested that DNT cells could migrate to lung/lung-related tissues to exert antigen-specific protection. Because mice were sensitized by intraperitoneal injections of OVA, it is reasonable that the mesenteric lymph node (mesenteric LN) showed an increased percentage of OVA DNT cells but not MOG DNT cells.

To determine whether OVA DNT cells could inhibit cytokine secretion by inflammatory $\mathrm{CD}^{+} \mathrm{T}$ cells, we investigated cytokine-secreting $\mathrm{CD}^{+}{ }^{+} \mathrm{T}$ cells in the lungs after OVA DNT treatment (Fig. 3a). OVA DNT-treated mice showed significantly decreased numbers of IL-4- and IL-21-secreting lung CD4 ${ }^{+}$ $\mathrm{T}$ cells compared to untreated mice. Meanwhile, we did not find significant differences in IL-13, IL-17 or IFN- $\gamma$ secretion by CD $4^{+}$ T cells between control and OVA DNT-treated mice. Prominent decreases in serum IL-4 and IL-5 levels and BAL fluid IL-4, IL-5 and IL-21 levels in OVA DNT-treated mice were also revealed (Fig. 3b). Moreover, OVA DNT treatment also markedly decreased the OVA-specific IgG and IgE concentrations in serum and BAL fluid (Fig. 3c).

Overall, these observations indicated that OVA DNTs selectively homed in to lung/lung-related tissues and suppressed IL-4, IL-21, and OVA-specific antibody production in an OVAinduced asthma model.

DNT treatment reduced the number of Tfh cells and CD11b ${ }^{+}$ DCs. Tfh cells are specialized providers of $\mathrm{T}$ cell helper cells for IL-4, IL-21, and antibody production in allergic airway diseases $^{8,18}$. We detected significant decreases in the frequency and total numbers of lung and BAL Tfh cells after OVA DNT treatment (Fig. 4a, Supplementary Fig. 1B). Meanwhile, the changes in the proportions of lung CD4 ${ }^{+} \mathrm{T}$ cells and Foxp3 ${ }^{+}$Treg cells were not statistically significant (Fig. 4b, Supplementary Fig. 1B). As powerful antigen-presenting cells, $\mathrm{CD} 11 \mathrm{~b}^{+}$proinflammatory DCs are responsible for Tfh cell-dependent antibody responses ${ }^{19}$. Our data showed that the frequencies and total numbers of lung and mLN CD $11 b^{+}$DCs were decreased significantly after OVA DNT treatment (Fig. 4c, Supplementary Fig. 1C). Additionally, the proportion of the total CD11 $\mathrm{c}^{+} \mathrm{MHC}-\mathrm{II}^{+} \mathrm{DC}^{\mathrm{D}}$ population was also decreased after OVA DNT treatment. However, we observed no significant change in the anti-inflammatory $\mathrm{CD}_{103}{ }^{+} \mathrm{DC}$ population (Fig. 4d). The number of B cells, which produce antibodies, was also decreased significantly in the lungs, mLN and BAL fluid (Fig. 4e, Supplementary Fig. 1B).

To investigate the impact of OVA DNTs on DCs, we assessed DCs in cocultures with OVA DNTs for 3 days in vitro (Fig. $4 \mathrm{f}-\mathrm{h}$ ). As shown in Fig. 4f, the proportions of total CD11b ${ }^{+}$DCs and 
a

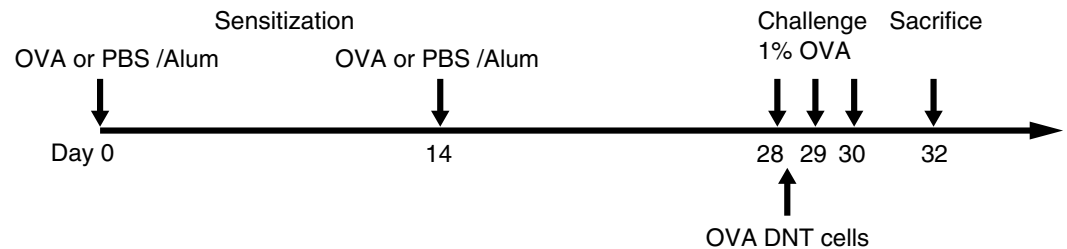

b
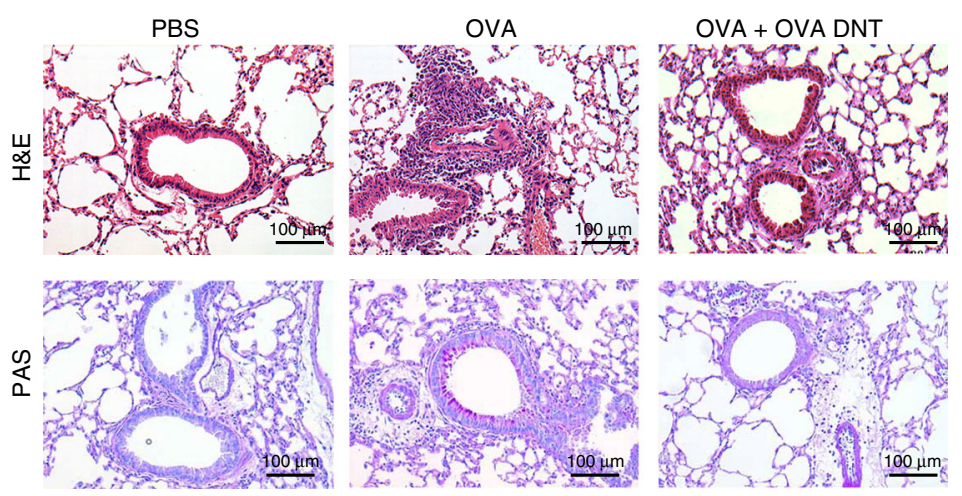

C

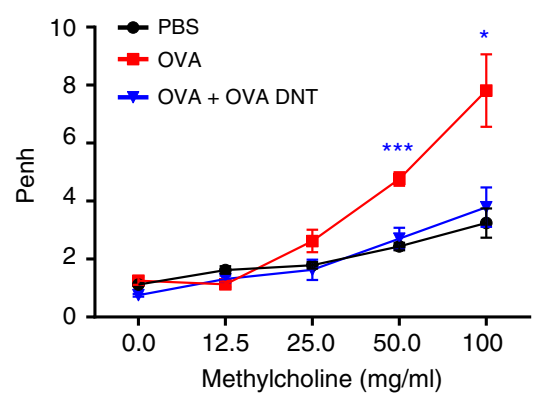

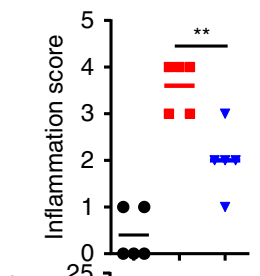

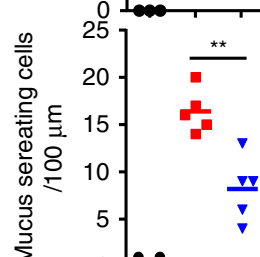

$\sum$
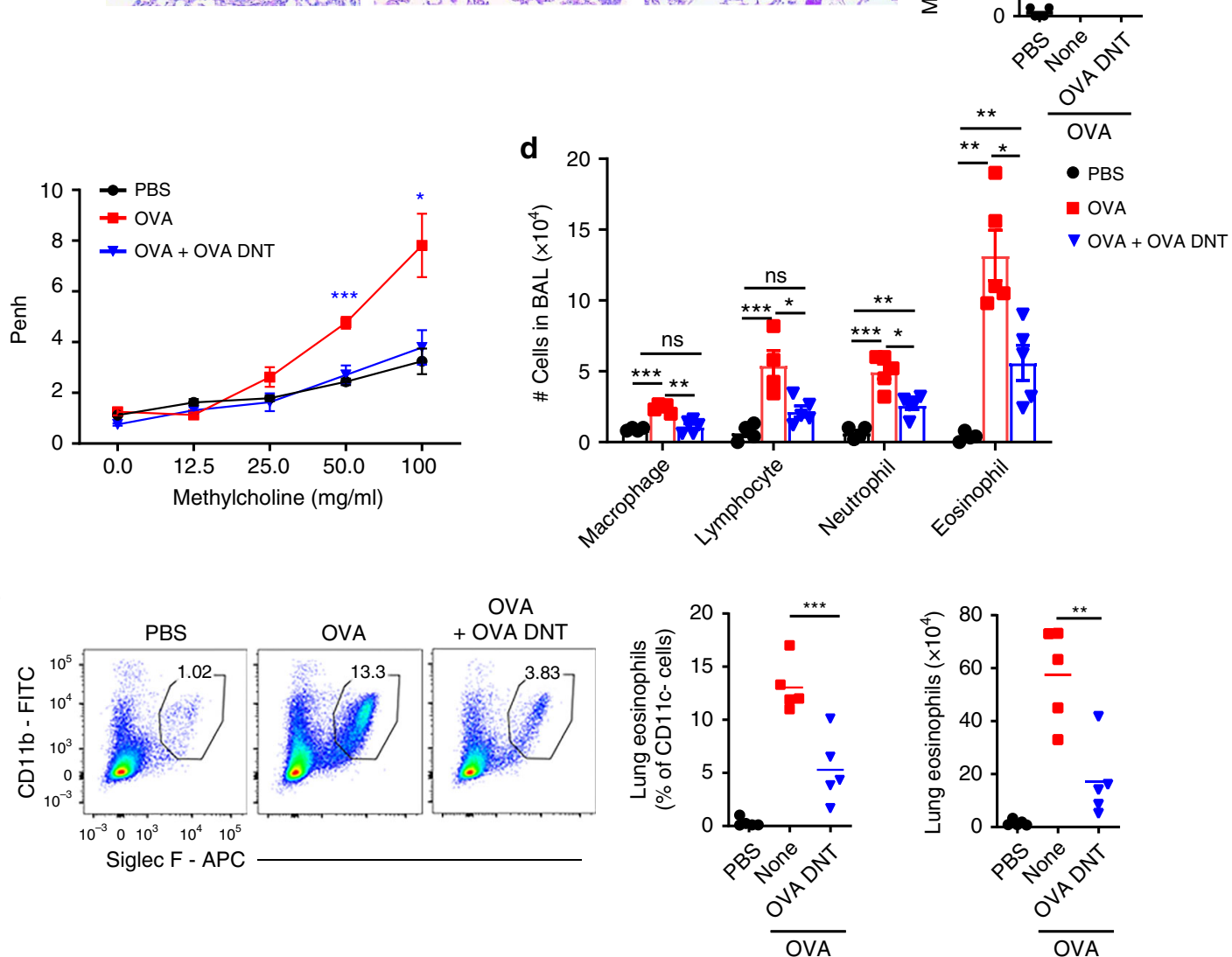

Fig. 1 OVA DNTs suppressed OVA-induced airway inflammation. a Schematic representation of the experimental procedure. Mice were sensitized with two intraperitoneal injections of ovalbumin (OVA) or PBS in an alum adjuvant at days 0 and 14 . The mice received $2 \times 10^{6}$ OVA-primed DNT cells (OVA DNTs) by intravenous adoptive transfer after the first 1\% OVA aerosol challenge on day 28. The mice were challenged daily for the next two days and sacrificed $48 \mathrm{~h}$ after the last aerosol challenge. $\mathbf{b}$ Lung sections were stained with H\&E and PAS to measure the numbers of infiltrated inflammatory cells and mucus-secreting cells. (Scale bars, $100 \mu \mathrm{m}$ ). c The airway hyperreactivity index and the Penh values were investigated $24 \mathrm{~h}$ after the last challenge. d After the mice were sacrificed, the bronchoalveolar lavage (BAL) fluid was collected and stained with Diff-Quik stain. Cells from the BAL fluid were counted and classified as macrophages, lymphocytes, neutrophils or eosinophils. e The percentage and numbers of eosinophils (Siglec $\mathrm{F}^{+} \mathrm{CD} 11 \mathrm{~b}^{+} \mathrm{CD} 11 \mathrm{c}^{-}$) in the lung were assessed by flow cytometry. The results are representative of 4-5 experiments with similar results. Data are shown as the mean \pm SEM; $n=5$ mice per group. One-way ANOVA was used to calculate significance. ${ }^{\star} P<0.05 ;{ }^{\star \star} P<0.01 ;{ }^{\star \star \star} P<0.001$. The source data are provided as a source data file 

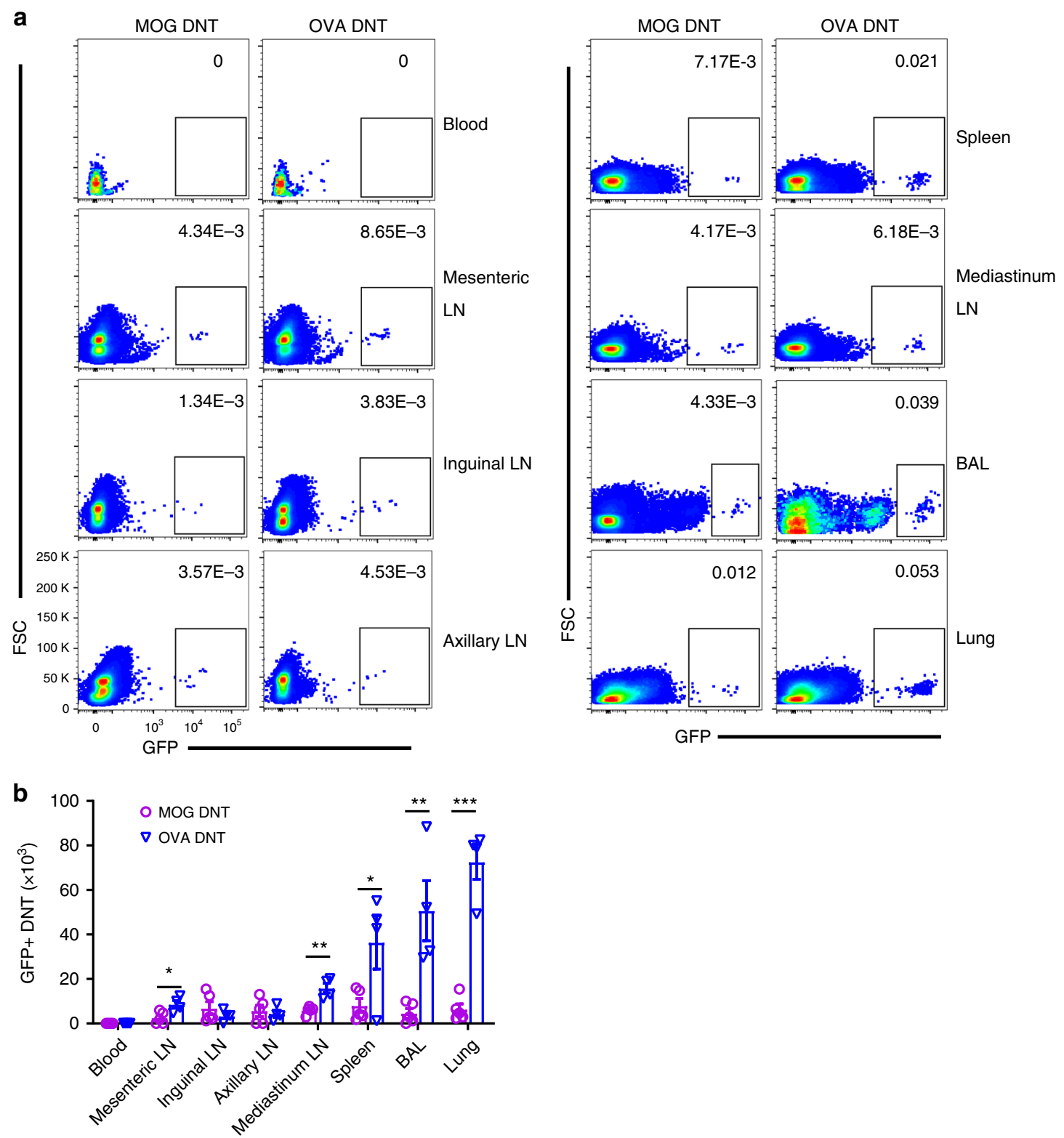

Fig. 2 OVA DNTs homed in to the lung to exert a protective effect. GFP+CD4 ${ }^{+}$T cells were converted to OVA or MOG DNTs via stimulation with the $\mathrm{OVA}_{323-339}$ or $\mathrm{MOG}_{35-55}$ peptide. GFP+ DNTs were used to treat OVA-induced asthma. $\mathbf{a}$ The percentages and $\mathbf{b}$ numbers of GFP+ cells in terms of the total cells in the lymphoid tissues were assessed by flow cytometry. Data are shown as the mean $\pm \mathrm{SEM} ; n=4$ mice per group. Student's $t$-test was used to calculate significance. ${ }^{\star} P<0.05 ;{ }^{\star \star} P<0.01 ;{ }^{\star \star \star} P<0.001$. Source data are provided as a source data file

MHC-II ${ }^{+} \mathrm{CD} 11 \mathrm{C}^{+}$DCs were found to be decreased when they were cocultured with OVA DNTs. Additionally, OVA DNTs also inhibited the expression of the costimulatory molecules CD40 and CD86 by DCs (Fig. 4g). However, we found no significant change in the proportion of apoptotic DCs (Fig. 4h).

Furthermore, we stained OVA-primed DNTs with OVAspecific MHC class II tetramers (I-A ${ }^{\mathrm{b}} \mathrm{OVA}_{323-339}$ tetramers). Then, we cocultured OVA tetramer ${ }^{+}$or tetramer- OVA DNTs with lung DCs from OVA-induced allergic mice in vitro for 3 days. As shown in Fig. 4i, both the tetramer ${ }^{+}$and tetramer ${ }^{-}$ DNTs significantly decreased CD86 expression in DCs, and CD86 expression was markedly decreased when the DCs were cocultured with tetramer ${ }^{+}$DNTs. Moreover, tetramer ${ }^{+}$ DNT cells but not tetramer ${ }^{-}$DNT cells could also suppress MHC-II expression by DCs. These results indicated that OVA DNTs selectively inhibited lung DCs, and this inhibition might have been antigen-specific.
To verify whether OVA DNT cell-treated DCs could suppress Tfh and Th2 cell differentiation, we obtained lung DCs from mice treated or untreated with OVA DNT cells. Then, these DCs were cocultured with naive $\mathrm{CD} 4^{+} \mathrm{T}$ cells for 5 days. As shown in Fig. 4 j, the OVA DNT cell-treated lung DCs induced significantly lower levels of IL-21 and IL-4 production compared with DCs isolated from untreated mice.

Overall, these data suggested that OVA DNTs selectively reduced the proportion of lung DCs and inhibited their maturation, which contributed to decreased Tfh and Th2 cell differentiation.

Allergen-specific inhibition of inflammation by OVA DNTs. Based on the observation that OVA DNTs efficiently inhibited OVA-induced allergic airway inflammation, we questioned whether OVA DNTs acquired allergen specificity after $\mathrm{OVA}_{323-339}$ peptide stimulation. $\mathrm{CD}^{+} \mathrm{T}$ cells were converted to 
a
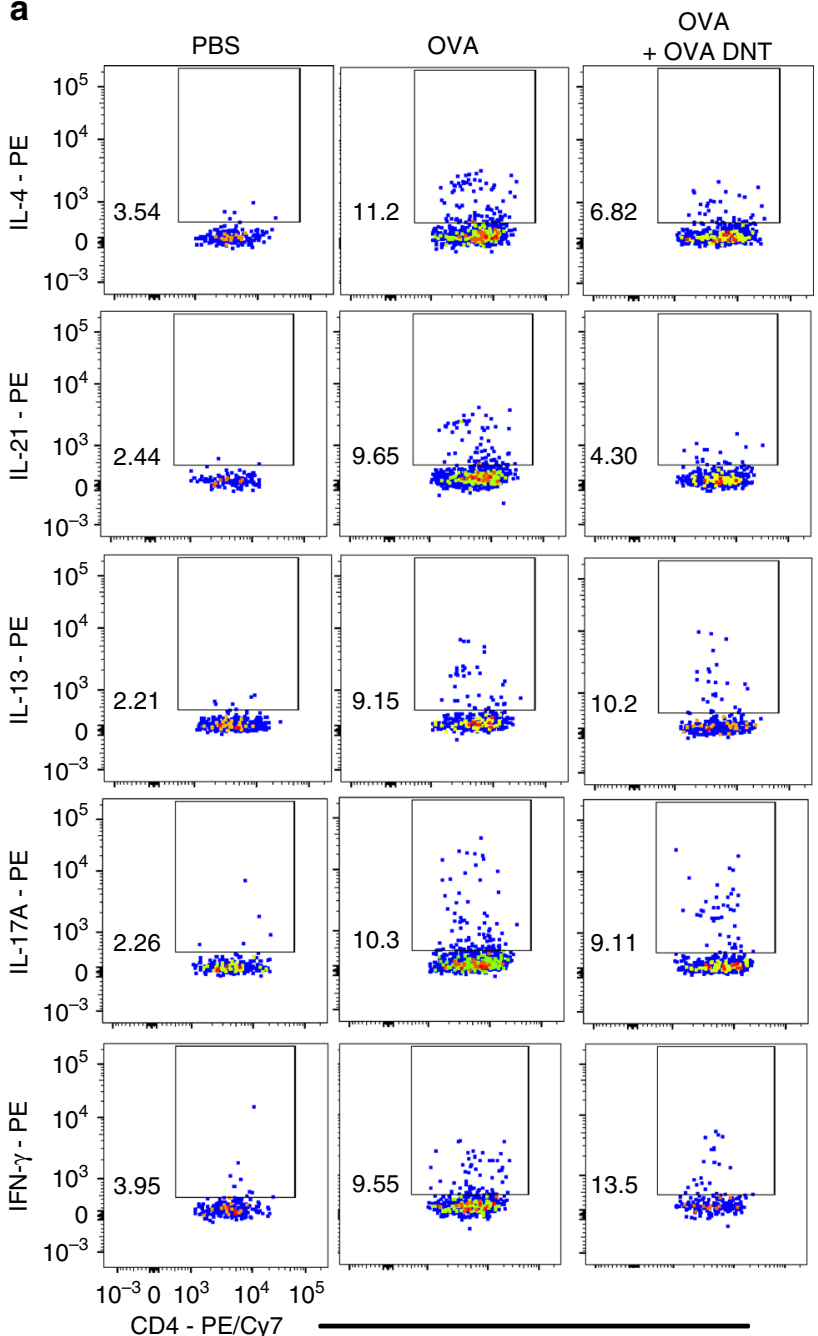

CD4 - PE/Cy7
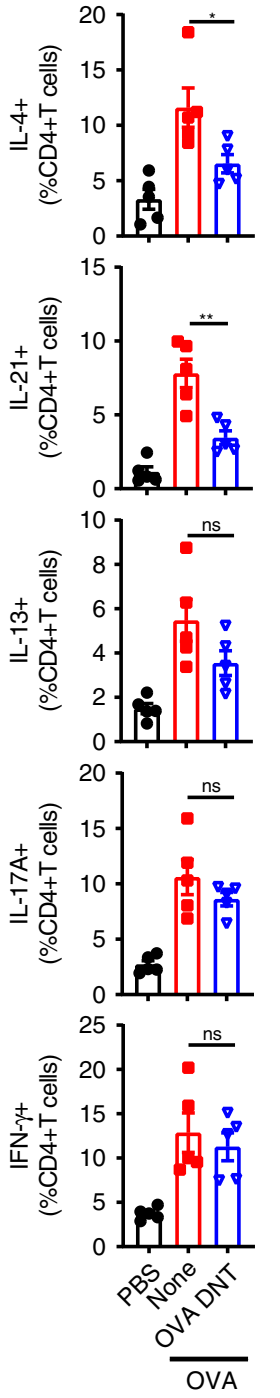

b
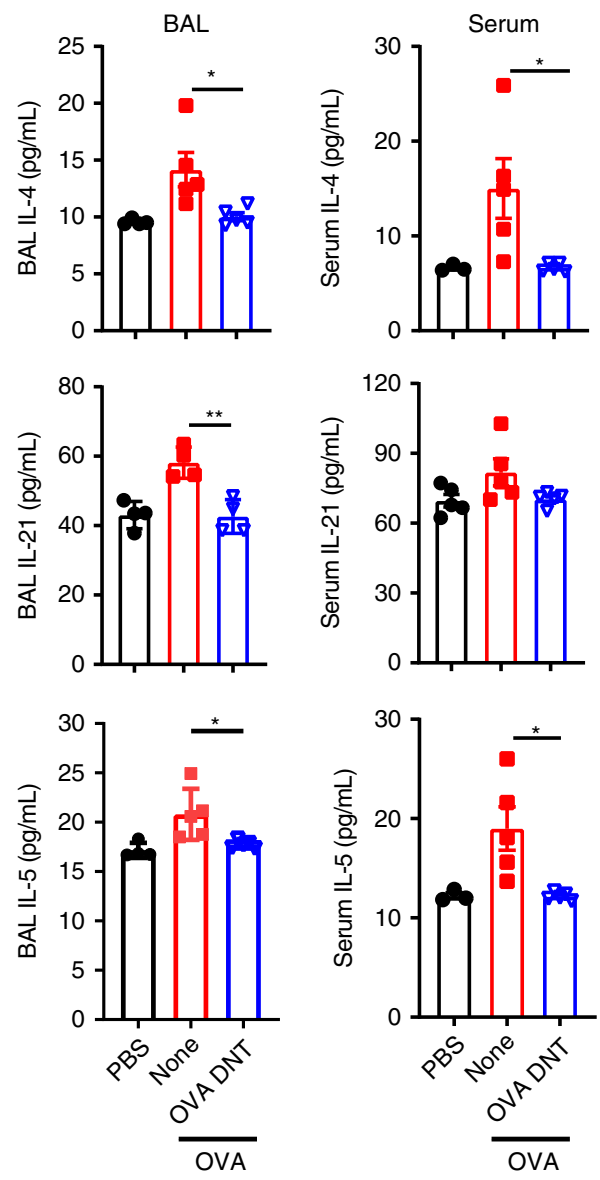
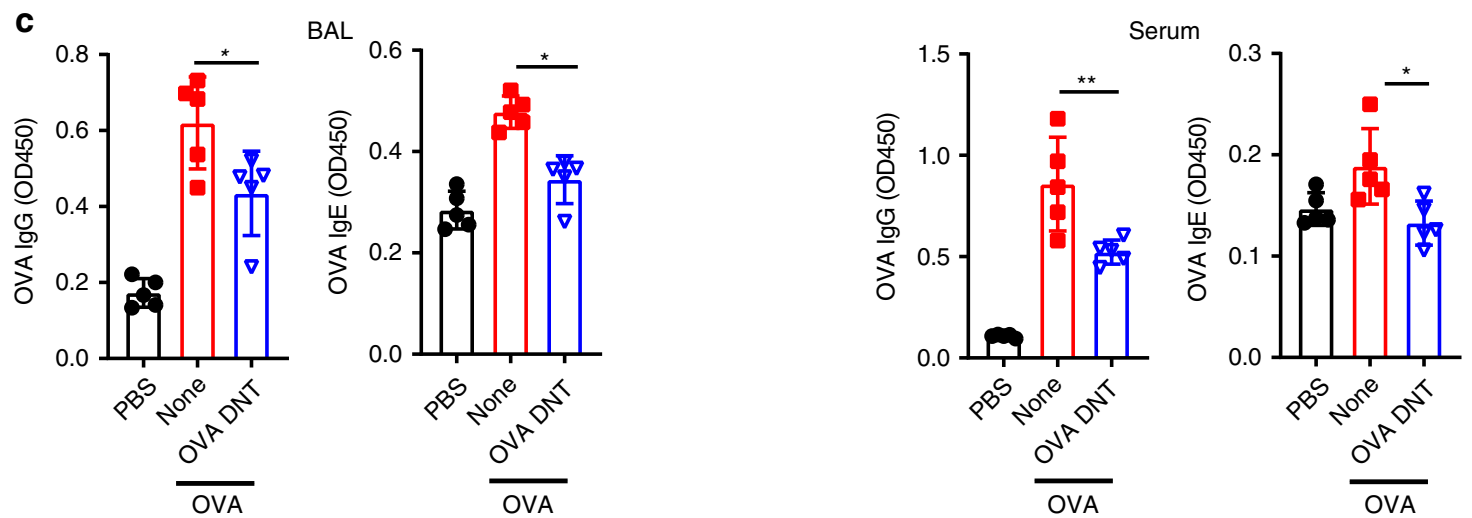

Fig. 3 OVA DNTs suppressed cytokine and OVA-specific Ig production. OVA-sensitized mice were treated with an intravenous transfer of OVA DNTs after the first OVA challenge. The mice were challenged daily for the next two days and sacrificed $48 \mathrm{~h}$ after the last aerosol challenge. a Inflammatory cytokine-secreting lung CD4 ${ }^{+}$T cells were measured by flow cytometry. $\mathbf{b}$ The BALF and serum cytokine levels were assessed by ELISA. $\mathbf{c}$ The levels of OVA-specific BALF and serum IgG/lgE were assessed by ELISA. Data are shown as the mean $\pm S E M ; n=4-5$ mice per group. One-way ANOVA was used to calculate significance. ${ }^{\star} P<0.05 ;{ }^{\star \star} P<0.01$. Source data are provided as a source data file 

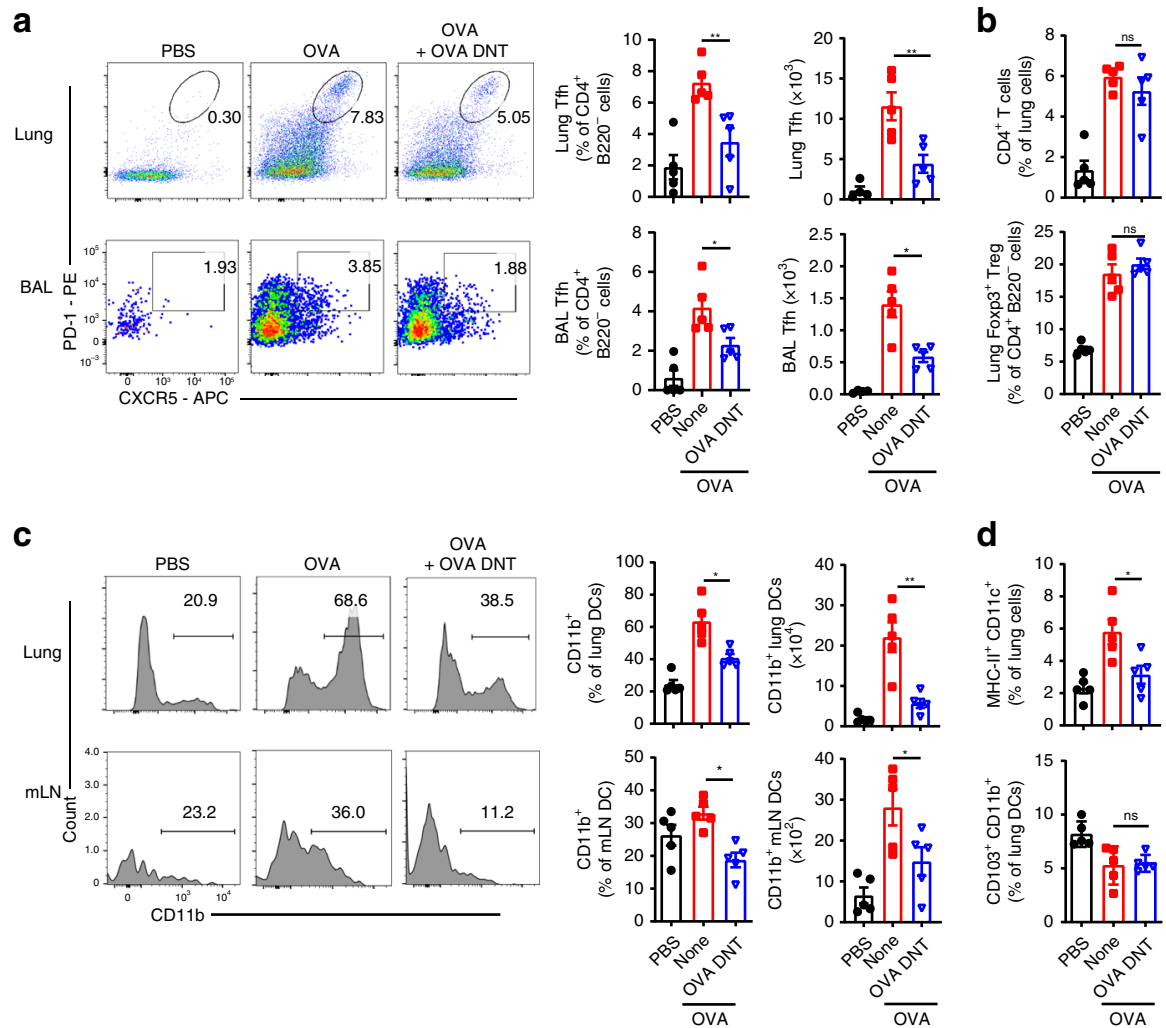

d
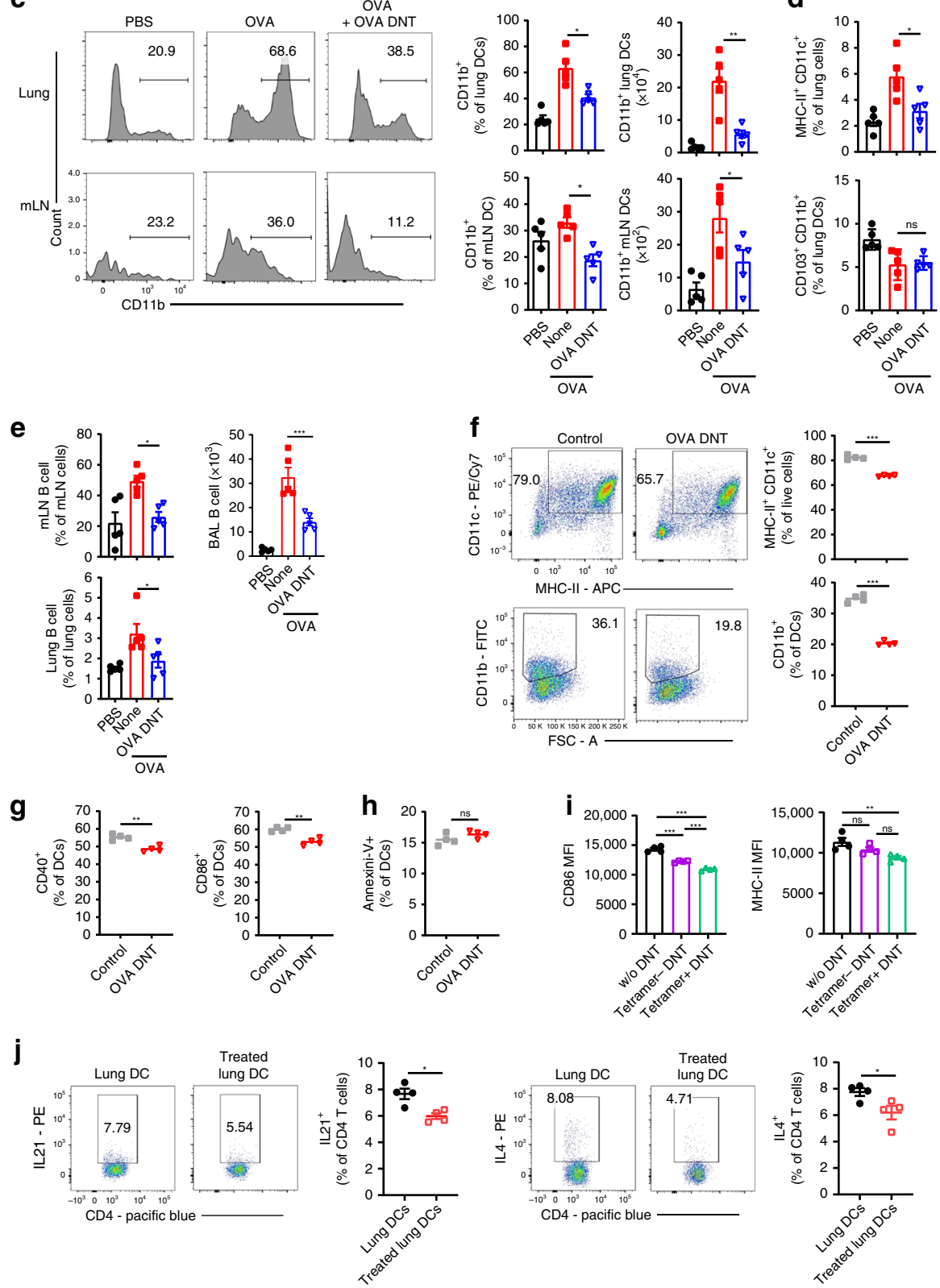

DNT cells with either $\mathrm{OVA}_{323-339}$ peptide or an unrelated peptide $\left(\mathrm{MOG}_{35-55}\right)$. No differences in the expression of CD11b, CD11c, MHCII, or CXCR5 were found between OVA DNTs and MOG DNT cells (Supplementary Fig. 3). C57BL/6 mice were sensitized, challenged with OVA and treated with OVA DNTs or MOGprimed DNT cells (MOG DNTs) as previously described. Intriguingly, the MOG DNTs failed to inhibit OVA-induced allergic airway inflammation and lung eosinophil accumulation 
Fig. 4 OVA DNT treatment selectively inhibited Tfh cells and CD11b+ DCs. OVA-sensitized mice were treated with an intravenous transfer of OVA DNTs after the first OVA challenge. The mice were challenged daily for the next two days and sacrificed $48 \mathrm{~h}$ after the last aerosol challenge. a The lung and BALF Tfh cell (CD4+B220-CXCR5+PD-1+), b CD4+ ${ }^{+}$cell $\left(C D 4^{+}{ }^{+}\right.$2220-) and Treg cell $\left(C D 4^{+}{ }^{+}\right.$222--Foxp3 $\left.{ }^{+}\right)$proportions were measured by flow cytometry. c The lung and mLN CD11b+ DC (CD11c + MHC-II+CD11b+), d DC (CD11c + MHC-9II+) and CD103+ DC (CD11 $\left.\mathrm{c}^{+} \mathrm{MHC}-\mathrm{II}^{+} \mathrm{CD} 103^{+} \mathrm{CD} 11 \mathrm{~b}^{-}\right)$ proportions were measured by flow cytometry. e The proportions of $B$ cells (B220 ${ }^{+} C D 4^{-}$) in the $\mathrm{mLN}$ (mediastinum lymph node), $B A L F$ and lungs were measured by flow cytometry. OVA-stimulated bone marrow cells were cocultured with OVA DNTs and stimulated with GM-CSF (20 ng/ml) for 3 days to test the direct effect of OVA DNTs on OVA DC proliferation and differentiation. $\mathbf{f}$ The proportions of bone marrow-derived DCs and CD11b+ DCs were measured by flow cytometry. The direct effects of OVA DNTs on $\mathbf{g}$ costimulatory molecule expression and $\mathbf{h}$ apoptosis in DCs were measured by flow cytometry. i OVA tetramer ${ }^{+}$and tetramer- DNT cells were sorted by flow cytometry from OVA-primed DNT cells. Tetramer ${ }^{+}$or tetramer ${ }^{-}$DNT cells were cocultured with lung DCs from allergic asthma mice for 3 days. The MFIs of CD86 and MHC-II in DCs were measured by flow cytometry. $\mathbf{j}$ Lung DCs $\left(2.5 \times 10^{4}\right)$ from OVA DNT cell-treated or -untreated asthma mice were cocultured with $1 \times 10^{5}$ naive CD4+ T cells for 3 days. IL21- and IL4-secreting $\mathrm{CD}^{+} \mathrm{T}$ cells were measured by flow cytometry. Data are shown as the mean $\pm \mathrm{SEM} ; n=4-5$ mice per group. One-way ANOVA and Student's $t$-test were used to calculate significance. ${ }^{\star} P<0.05$; ${ }^{\star \star} P<0.01 ;{ }^{\star \star \star} P<0.001$. Source data are provided as a source data file

(Fig. 5a, b). Similarly, we found no statistically significant decreases in the accumulation of DCs, CD11b ${ }^{+}$DCs and Tfh cells after MOG DNT treatment (Fig. 5c, d).

To further confirm the antigen-specific suppression of DNT cells in allergic asthma, we induced allergic asthma with HDM (house dust mite) extract in BALB/c mice (Supplementary Fig. 4A). HDM or OVA-primed DNT cells were adoptively transferred to mice with HDM-induced allergic asthma. Similar to the previous results, HDM DNT cells, rather than OVA DNT cells, significantly ameliorated inflammatory cell infiltration (Supplementary Fig. 4B) and reduced the accumulation of eosinophils (Supplementary Fig. 4C), Tfh cells (Supplementary Fig. 4D) and CD11b+ DCs (Supplementary Fig. 4E).

These results indicated that DNT cells suppressed allergic airway inflammation while maintaining allergen specificity.

Lag3 depletion reduced suppressor activity of OVA DNTs. CD4 molecules are essential coreceptors of $\mathrm{T}$ cell receptors that contribute to the recognition of peptide antigen presented by MHCII molecules of antigen-presenting cells. The way in which DNT cells retain antigen specificity and recognize OVA peptides presented by dendritic cells without $\mathrm{CD} 4$ expression is still unknown. Lag3 has been reported to be a molecule that can bind to MHC-II with higher affinity than $\mathrm{CD} 4{ }^{20}$. We, therefore, measured Lag3 expression by DNT cells. Compared with $\mathrm{CD}^{+}$ $\mathrm{T}$ cells, DNT cells showed significantly upregulated Lag3 expression according to real-time PCR results (Fig. 6a). The markedly increased expression of Lag3 was also confirmed by flow cytometry (Fig. 6b).

To reveal whether Lag3 expression by DNT cells contributes to antigen specificity in DNT cells, we compared the suppressive function of Lag3-deficient DNT cells with that of WT DNT cells in vivo. $\mathrm{CD} 4{ }^{+} \mathrm{CD} 25^{-} \mathrm{T}$ cells from WT or $\mathrm{Lag}^{-/-}$mice were converted to OVA DNTs. As shown in Fig. 6c, the adoptive transfer of Lag3-/- OVA DNTs failed to ameliorate OVAinduced airway inflammation. Additionally, the percentages of eosinophils, DCs and $\mathrm{CD}_{1} 1 \mathrm{~b}^{+}$DCs showed no significant differences between the Lag3-/- OVA DNT-treated group and the control groups (Fig. 6d, e). Given the intimate link between DCs and Tfh cells, we also observed no significant change between the Tfh cell population of the Lag3-1- OVA DNTtreated group and that of the control groups (Fig. 6f).

DNT cells exert control over immune responses mainly through the perforin/granzyme and Fas/Fas L pathways ${ }^{13,15,21}$. To investigate whether the weakening of the immunosuppressive activity of the $\operatorname{Lag3}^{-/}$OVA DNTs was associated with the downregulation of these pathways, we assessed suppressive gene expression in DNT cells. As shown in Fig. 6g, no significant differences in granzyme B expression were observed between WT and Lag $^{-1-}$ OVA DNTs by flow cytometry. The mRNA expression levels of Prf1 and Fasl were also similar in WT and $\mathrm{Lag3}^{-/}$OVA DNTs (Fig. 6h). The proportion of apoptotic DNT cells increased slightly among the $\operatorname{Lag} 3^{-1-}$ cells, but the difference was not significant (Fig. 6i). Intriguingly, similar to $\mathrm{CD}^{+} \mathrm{T}$ cells ${ }^{22}$, Lag3 $^{-/-}$DNT cells expressed significantly increased levels of the cell activation marker CD69 and the proliferation marker Ki67 than WT DNT cells (Fig. 6j).

Overall, Lag3 depletion reduced the antigen-specific suppression of OVA DNTs, and this reduction in suppression was not related to DNT cell activation, apoptosis, or perforin, granzyme or Fas L expression.

Lag3 contributed to antigen recognition by DNT cells. To investigate the impact of Lag3 on antigen-specific recognition by DNT cells, we assessed the WT and Lag $^{-1-}$ OVA DNTs by staining them with OVA-specific MHC class II tetramers (I-A ${ }^{b}$ $\mathrm{OVA}_{323-339}$ tetramers) (Fig. 7a). A significantly higher proportion of I-A ${ }^{b}$ OVA $_{323-339}$ tetramer-positive cells was observed in the OVA DNT cells compared with either the OVA-primed Lag3-/DNT cells or the MOG-stimulated WT DNT cells. In contrast, the proportion of OVA tetramer-positive cells in the Lag3-/DNT cells primed with the $\mathrm{OVA}_{323-339}$ peptide was not significantly different from that in either the WT or Lag 3-deficient DNT cells that were stimulated with MOG peptide (Fig. 7a). To clarify whether Lag3 is also important for antigen-specific recognition by natural DNT cells, naive natural DNT cells from WT or Lag3-/- mice were cocultured with C57BL/6J mDCs, $50 \mathrm{ng} / \mathrm{ml} \mathrm{rmIL-2}$ and $1 \mu \mathrm{g} / \mathrm{ml} \mathrm{OVA}_{329-339}$ for 5 days. The activated and freshly isolated naive WT or $\mathrm{Lag}^{-1-}$ DNT cells were stained with OVA-specific MHC class II tetramers $\left(\mathrm{I}-\mathrm{A}^{\mathrm{b}}\right.$ OVA $_{323-339}$ tetramers). As shown in Supplementary Fig. 5, although the average OVA tetramer-positive cell percentage was lower in the natural DNT cells than the CD4 T cells that were stimulated to become DNT cells, a significantly higher proportion of $\mathrm{I}^{-\mathrm{A}^{\mathrm{b}}} \mathrm{OVA}_{323-339}$ tetramer-positive cells was still observed in the OVA-primed natural WT DNT population compared with either the OVA-primed Lag3 $3^{-/}$natural DNT cell or naive DNT cell population. These results indicated that Lag3 was also involved in the antigen recognition of natural DNT cells.

Recent evidence demonstrated that trogocytosis is important for antigen acquisition by DNT cells ${ }^{23}$. As shown in Fig. 7b, c, lung DCs from asthmatic mice were stained with the molecular probe $\mathrm{DiD}$, which is highly fluorescent when incorporated into membranes ${ }^{24}$, and cocultured with DNT cells for $24 \mathrm{~h}$. MHC-II molecule expression and $\mathrm{DiD}$ staining were markedly decreased in Lag $3^{-1-}$ DNT cells than in WT DNT cells. To observe the trogocytosis process directly, we cocultured $\mathrm{GFP}^{+}$DNT cells and lung DCs labeled with DiD. Confocal microscopy revealed that DiD-labeled fragments of DC plasma membranes were translocated into DNT cells (Fig. 7d). Moreover, the DCs and $\mathrm{GFP}^{+}$ 
a
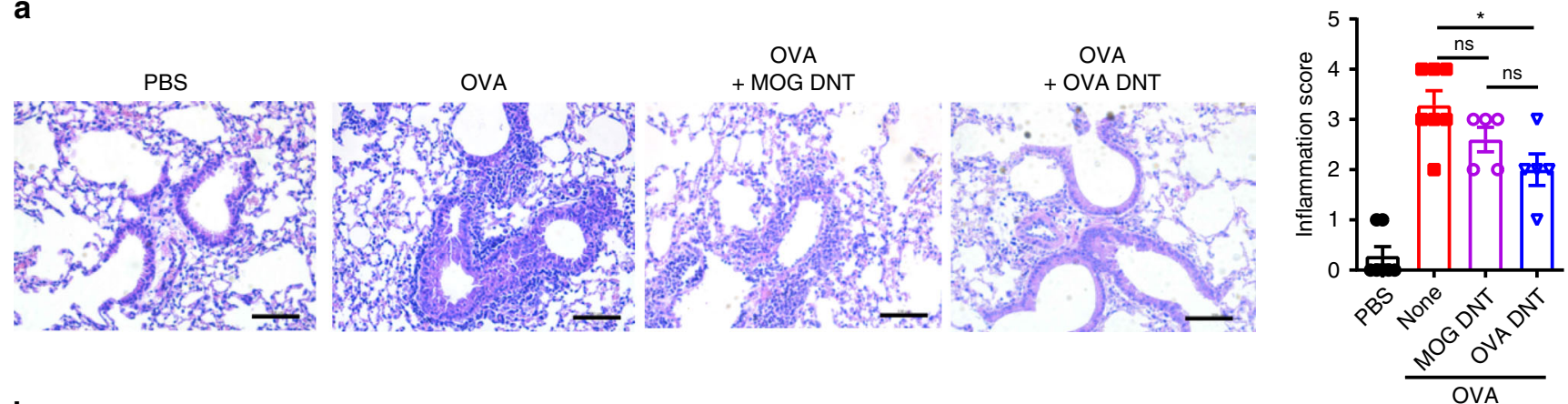

b
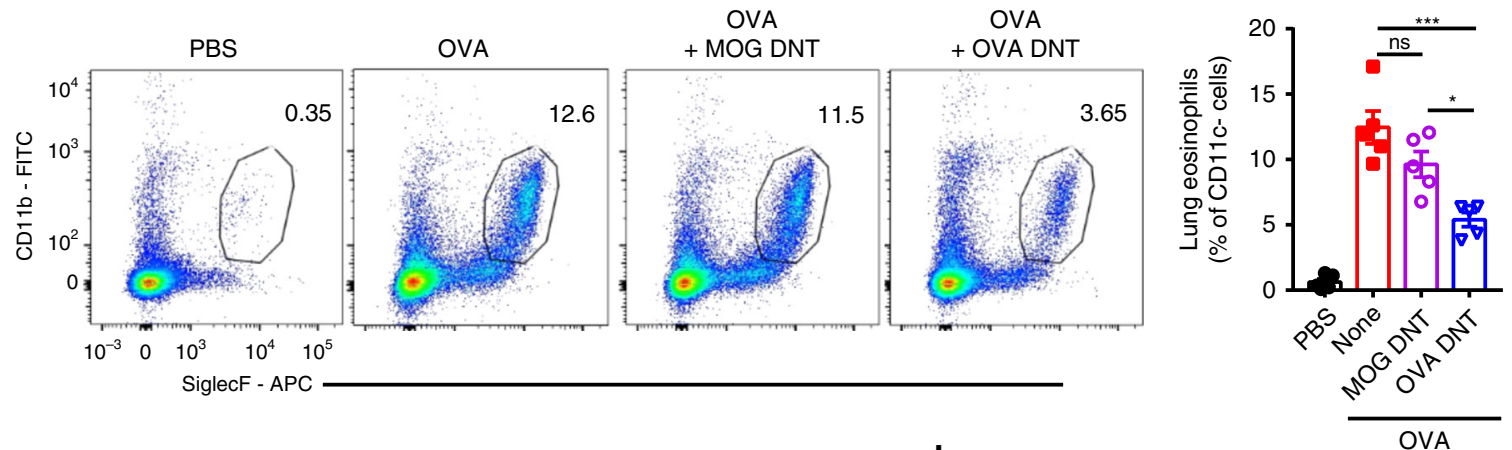

C

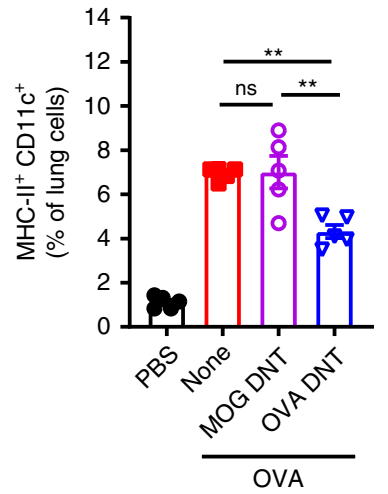

d

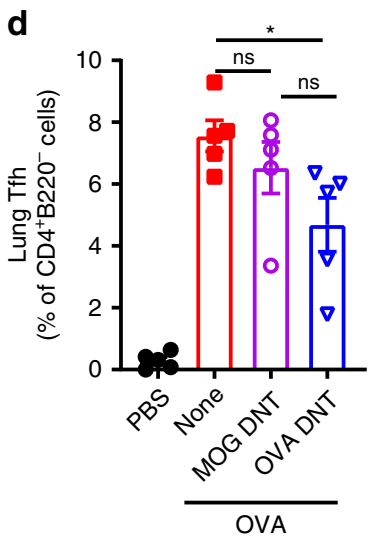

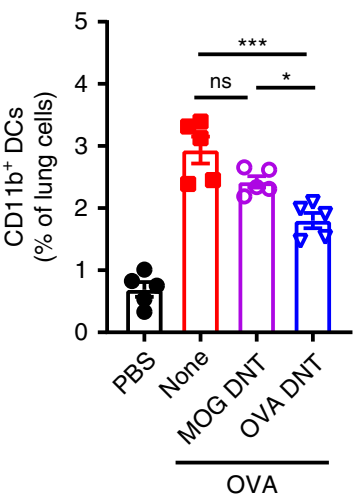

Fig. 5 OVA DNTs specifically protected mice against OVA-induced airway inflammation. Mice received MOG DNTs or OVA DNTs by intravenous adoptive transfer to treat OVA-induced airway inflammation. a Lung sections were stained with H\&E to measure the accumulation of infiltrating inflammatory cells. (Scale bars, $100 \mu \mathrm{m}$ ). b Eosinophils (Siglec $\mathrm{F}^{+} \mathrm{CD} 11 \mathrm{~b}^{+} \mathrm{CD} 11 \mathrm{c}^{-}$) in the lung were assessed by flow cytometry. c Lung DCs $\left(\mathrm{CD} 11 \mathrm{~b}^{+} \mathrm{CD} 11 \mathrm{c}^{+} \mathrm{MHC}-\mathrm{II}^{+}\right)$and $\mathbf{d}$ Tfh cells (CD4+B220-CXCR5+PD-1+) were assessed by flow cytometry. The results are representative of two experiments with similar results. Data are shown as the mean $\pm \mathrm{SEM} ; n=5$ mice per group. One-way ANOVA was used to calculate significance. ${ }^{\star} P<0.05$; ${ }^{\star \star} P<0.01 ;{ }^{\star \star \star} P<0.001$. Source data are provided as a source data file

DNT cells were also stained for surface Lag3 and MHC-II, respectively. Interestingly, we observed that Lag3 was mainly enriched on the surfaces where DNT cells had had direct contact with DCs (Fig. 7e).

Overall, these data demonstrated that Lag3 was important for the interaction between DNT cells and antigen-presenting cells. DNT cells could acquire MHC-II molecules from dendritic cells to obtain antigen specificity with the assistance of Lag3.

\section{Discussion}

Current treatments for allergic and autoimmune diseases depend on nonspecific immune suppression and often lead to adverse reactions or other conditions in patients. Innovative strategies that target allergen-induced specific immune responses will provide the benefit of preventing unwanted adverse effects or deaths and improve the quality of life of patients.

DNT cells are a unique type of regulatory $\mathrm{T}$ cells and are essential for maintaining immune system homeostasis ${ }^{13,14}$. We previously identified the differentiation pathway that converts $\mathrm{CD}^{+} \mathrm{T}$ cells into DNT cells ${ }^{15,21} \cdot \mathrm{CD}^{+} \mathrm{T}$ cell-converted DNT cells potently suppressed vigorous allo- and autoimmune responses, prolonged islet and skin allograft survival, and prevented and cured autoimmune type 1 diabetes ${ }^{15-17}$.

In this study, to develop a cellular therapy for allergic asthma, we converted naive CD4 ${ }^{+} \mathrm{T}$ cells to OVA-specific DNT cells ex vivo. The adoptively transferred OVA-primed DNT cells mainly accumulated in the lungs, BALF and spleen to significantly inhibit OVA-induced airway inflammation and suppress mucus hypersecretion, bronchial hyperreactivity and the infiltration of eosinophils and lymphocytes. The protection from OVA-induced allergic airway inflammation mediated by DNT cells was mediated by the inhibition of Tfh cells and $\mathrm{CD}_{11 \mathrm{~b}}+$ DCs and the reduced secretion of IL-21, IL-4, and OVAspecific antibodies.

Tfh cells are a subset of $\mathrm{T}$ helper cells that provide specialized help to B cells and facilitate antibody production ${ }^{25}$. Additionally, 
a
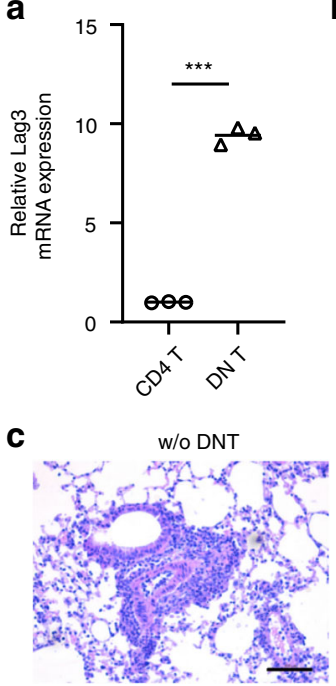

b

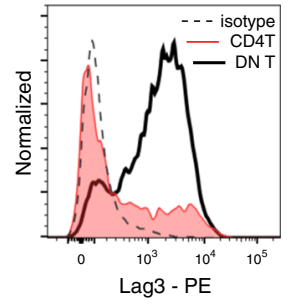

WT OVA DNT
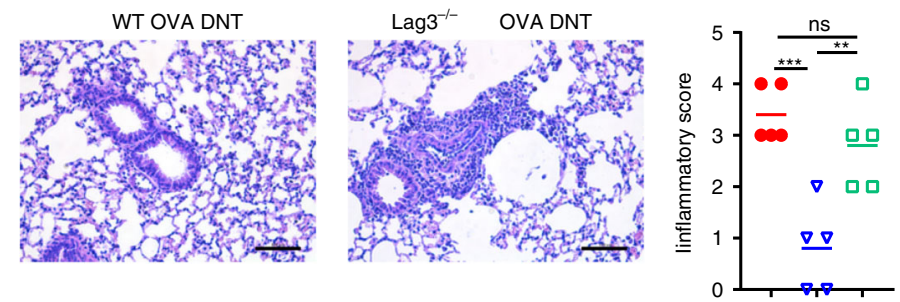

d

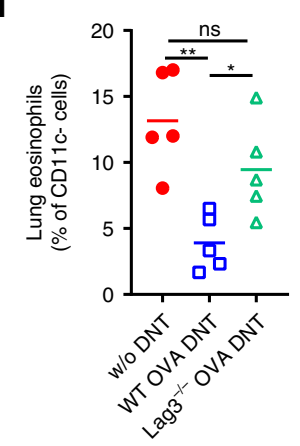

e

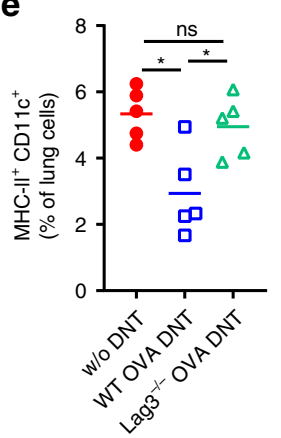

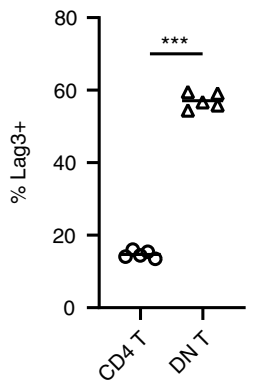

f

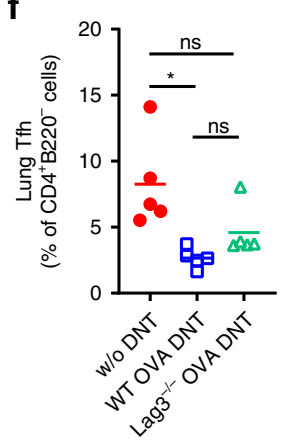

g
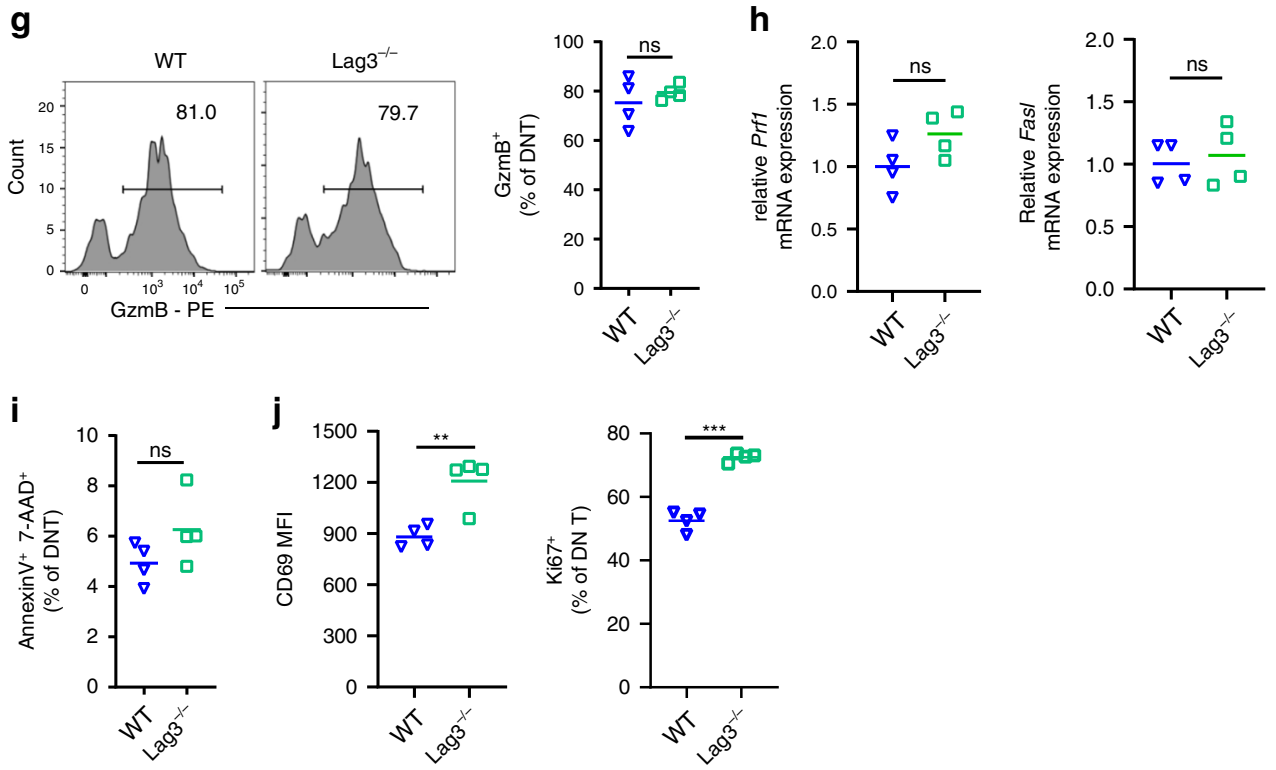

Fig. 6 Lag3 knockout reduced the antigen-specific suppression of OVA DNTs. Relative Lag3 mRNA expression in OVA DNTs and CD4 ${ }^{+}$T cells was measured by a real-time PCR and $\mathbf{b}$ flow cytometry. Mice received WT OVA DNTs or Lag3-/- OVA DNTs by intravenous adoptive transfer to treat OVA-induced airway inflammation. c Lung sections were stained with H\&E to measure the accumulation of infiltrating inflammatory cells

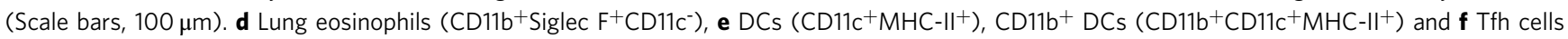
$\left(C D 4^{+}\right.$B220-CXCR5 + PD- $\left.{ }^{+}\right)$were assessed by flow cytometry. $\mathbf{g}$ GzmB expression in WT DNTs and Lag3-/- DNTs were measured by flow cytometry. h Relative Prf1 and Fasl mRNA expression levels in WT DNTs and Lag3-/- DNTs were measured by real-time PCR. i The apoptosis of DNT cells was detected by flow cytometry. $\mathbf{j}$ The expression of CD69 and Ki67 were detected by flow cytometry. Data are shown as the mean \pm SEM; $n=4-5$ mice per group. One-way ANOVA and Student's $t$-test were used to calculate significance. ${ }^{\star} P<0.05 ;{ }^{\star \star} P<0.01 ;{ }^{\star \star \star} P<0.001$. Source data are provided as a source data file 
a
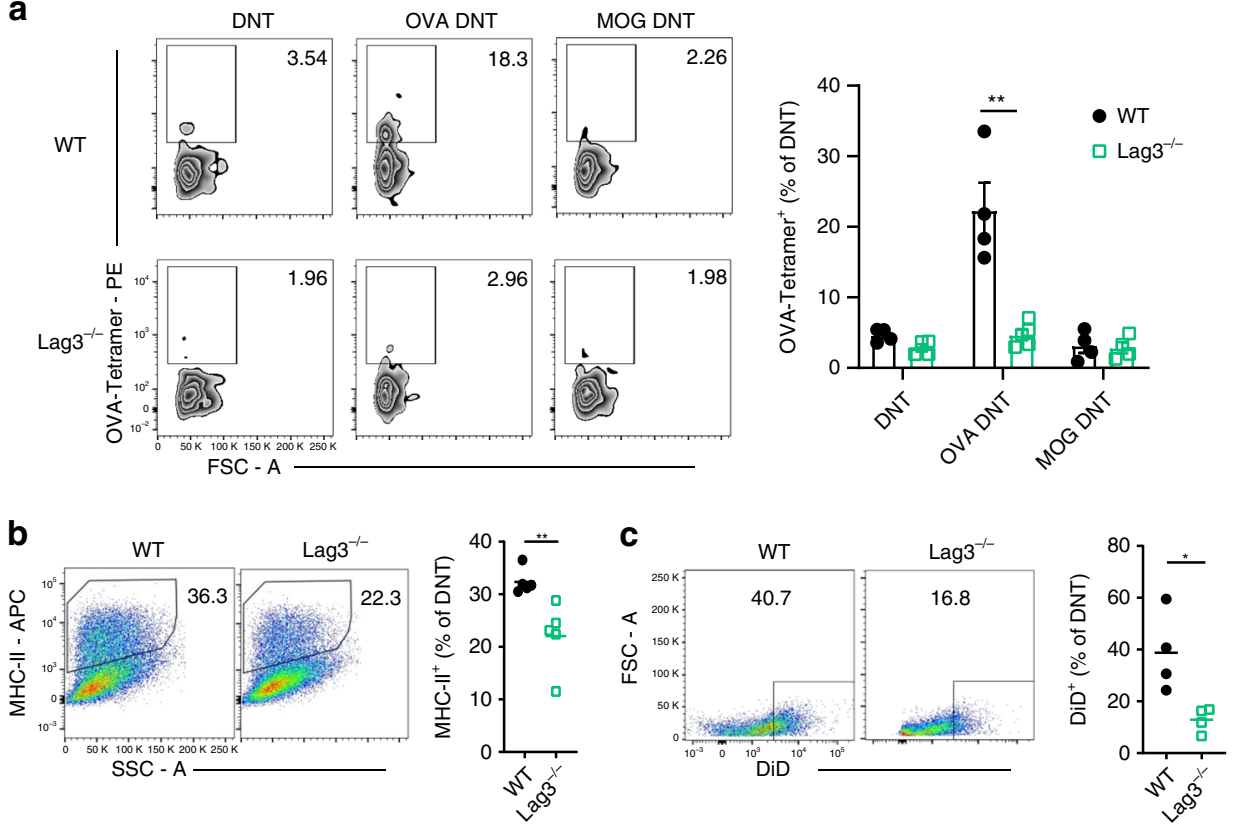

d
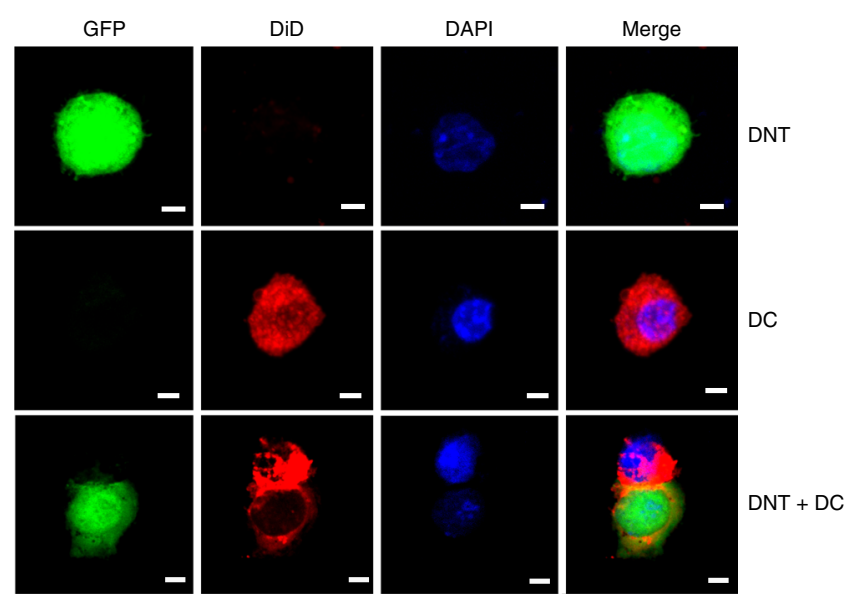

$\mathbf{e}$
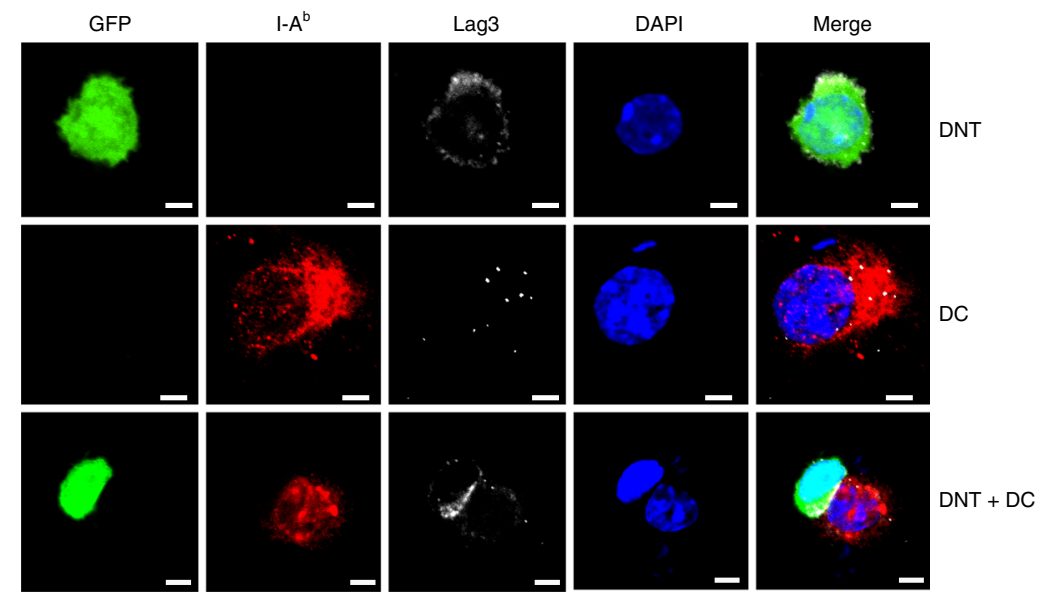

Fig. 7 The antigen-specific suppression of OVA DNTs was Lag3-dependent. a OVA-specific DNT cells were assessed by OVA-tetramer-PE staining. WT or Lag3-/- CFSE-labeled DNT cells were incubated with DiD-labeled DCs for $24 \mathrm{~h}$. b MHC-II molecule and c DiD capture by DNT cells after coculture were measured by flow cytometry. The results are representative of two experiments with similar results. d GFP+ DNT cells were analyzed by confocal fluorescence microscopy after being incubated with DiD-labeled lung DCs for $24 \mathrm{~h}$ (Scale bars, $5 \mu \mathrm{m}$ ). e I-A $\mathrm{A}^{\mathrm{b}}$ expression on DCs and Lag3 expression on GFP+ DNT cells were analyzed by confocal fluorescence microscopy. (Scale bars, $5 \mu \mathrm{m}$ ). Data are shown as the mean $\pm \mathrm{SEM} ; n=4-5$ mice per group. Student's $t$-test was used to calculate significance. ${ }^{\star} P<0.05 ;{ }^{\star \star} P<0.01$. Source data are provided as a source data file 
Tfh cells are responsible for the initiation of type 2 allergic asthma ${ }^{8,9,26}$. Our study shows that DNT cell treatment significantly reduced the proportion of Tfh cells and decreased IL-21 secretion in OVA-induced allergic airway disease, which demonstrated the direct effects of DNT cells on ameliorating allergic asthma. Tfh cell priming requires costimulatory signals from DCs in lymphoid tissues, and antigen presentation by DCs is essential for optimal antigen-specific Tfh cell development ${ }^{25}$. The key role of CD11b+ DCs in initiating allergic responses has been extensively demonstrated ${ }^{27,28}$. Additionally, CD11b- DCs, especially $\mathrm{CD}_{103^{+}}{ }^{+} \mathrm{DCs}$, seem to restrain allergic airway inflammation ${ }^{29,30}$. Our data herein show that OVA DNT treatment induced a selective reduction in the proportion of $\mathrm{CD}_{11 \mathrm{~b}}{ }^{+} \mathrm{DCs}$, which are the predominant Tfh-promoting DC subset. We did not observe any appreciable changes in regulatory $\mathrm{CD} 103^{+} \mathrm{DCs}$ or Foxp $3^{+}$Treg cells after OVA DNT treatment. In vitro coculture of bone marrow-derived DCs and DNT cells revealed the significant suppressive effect of DNT cells on the proliferation, differentiation and costimulatory molecule expression of $\mathrm{CD}_{11 \mathrm{~b}^{+}}$ DCs. OVA DNT cell-treated lung DCs induced significantly reduced IL-21 and IL-4 production compared with DCs isolated from untreated mice. These data suggested that DNT cells have direct suppressive effects on $\mathrm{CD} 11 \mathrm{~b}^{+} \mathrm{DCs}$, which repress further Tfh cell activation and cytokine secretion.

Previous studies demonstrated that both murine and human DNT cells suppress allogeneic immune responses and autoimmune responses in an Ag-specific fashion ${ }^{11,12,15,16}$. T cells have been shown to acquire MHC class I and class II molecules from antigen-presenting cells $s^{31,32}$. Ford et al. showed that naive DNT cells can also acquire alloantigens through trogocytosis in vivo ${ }^{23}$. In an allogeneic hematopoietic stem cell transplantation study, DNT cells acted as MHC class I/peptide reactive T cells and contributed to antiviral immune responses; these conclusions were supported by an HLA-A ${ }^{\star} 24: 02 \mathrm{EBV}$ tetramer test and the observation of EBV (BZLF1)-specific cytokine secretion in response to certain peptides ${ }^{33}$. Leishmania-reactive DNT cells were reported to be MHC-II restricted, as anti MHC-II antibodies blocked the proliferation and IFN- $\gamma$ production of both $\mathrm{CD} 4{ }^{+}$ and DNT cells in a dose-dependent manner. In addition, Leishmania-infected BMDCs from MHC-II KO mice failed to induce proliferation and IFN- $\gamma$ production in $\mathrm{DN}$ and $\mathrm{CD} 4^{+}$ $\mathrm{T}$ cells. In contrast, proliferation and IFN- $\gamma$ production in DNT cells were minimally affected following coculture with infected BMDCs from CD1d KO mice, confirming that DNT cells are mostly MHC-II restricted ${ }^{34}$. However, as DNT cells lack the expression of the MHC-II coreceptor $\mathrm{CD} 4$, the recognition of MHC-II and maintenance of antigen specificity by DNT cells remain unclear.

In our study, compared with $\mathrm{CD} 4^{+} \mathrm{T}$ cells, DNT cells exhibited elevated Lag3 expression. Lag3 is a transmembrane protein that belongs to the immunoglobulin superfamily. A comparative peptide analysis of Lag3 and CD4 showed the close relationship between the two molecules ${ }^{35}$. Huard et al. demonstrated that compared with the corresponding CD4 molecule, both human and mouse Lag3 show 100-fold higher avidity towards MHC-II ${ }^{20}$. Intriguingly, in our study, a significantly higher proportion of I$\mathrm{A}^{\mathrm{b}} \mathrm{OVA}_{323-339}$ tetramer-positive cells was observed among OVAprimed DNT cells compared with $\mathrm{Lag}^{-/-}$DNT cells. Lag3deficient DNT cells showed weak MHC-II recognition and therapeutic effects on OVA-induced asthma. Furthermore, we observed Lag3 accumulation at the surfaces of contact between DNT cells and DCs. These results indicated the important role of Lag3 in the interaction of DNT cells and DCs. Trogocytosis is a cell-cell contact-dependent membrane transfer process that usually occurs between lymphocytes and antigen-presenting cells $^{36}$. In this study, we also identified the intercellular transfer between MHC-II and the plasma membrane mediated by the Lag3 molecule between DNT cells and DCs. Thus, our study revealed that DNT cells exhibited trogocytosis and attained antigen specificity with the assistance of Lag3.

Lag3 is one of the putative markers of mouse and human $\mathrm{T}$ regulatory type 1 cells $(\operatorname{Tr} 1)$ cells ${ }^{37}$. Tr1 cells preferentially produce IL-10 and exert immunosuppressive effects. The adoptive transfer of $\mathrm{Lag} 3^{+} \mathrm{CD} 49 \mathrm{~b}^{+} \mathrm{CD} 4{ }^{+} \mathrm{Tr} 1$ cells ameliorates allergic asthma ${ }^{10}$. However, whether Lag3 regulates the immunosuppressive function of $\operatorname{Tr} 1$ cells is unclear. Lag3 was also reported to be essential for Foxp $3^{+}$Treg functioning, as Lag $3^{-/-}$Tregs exhibit reduced suppressive activity ${ }^{38}$. It was reported that Lag3 intrinsically limited Treg proliferation and functioning at sites of inflammation in an autoimmune diabetes model ${ }^{39}$. The adoptive transfer of Lag3-deficient Tregs was unable to attenuate allergic inflammation, demonstrating the critical role of the IL-27/Lag3 axis in mediating Treg control of allergic inflammation ${ }^{40}$. Unlike Tr1 cells and Foxp $3^{+}$Tregs, which both highly express Lag3, DNT cells do not produce IL-10 ${ }^{21}$ and show no Foxp $3^{15,21}$ expression. Lag3 expression on DNT cells contributes to MHC-II antigen recognition and thus affects antigen-specific immune regulation by DNT cells.

In conclusion, ex vivo-generated, $\mathrm{CD} 4 \mathrm{~T}$ cell-converted, allergen peptide-primed DNT cells exerted potent antigen-specific immune regulatory effects in allergen-induced mouse asthma models. Elevated Lag3 expression and trogocytosis contributed to MHC-II antigen recognition by DNT cells. These data support the concept and the feasibility of potentially utilizing this cellbased allergen-specific therapeutic approach for the clinical treatment of allergy and asthma.

\section{Methods}

Mice. Wild type (WT) C57BL/6J, C57BL/6J-GFP, BALB/c, and Lag3 ${ }^{-/-}$mice were purchased from Jackson Laboratory. The animals were housed and bred under specific pathogen-free conditions in a temperature-controlled environment under $12 \mathrm{~h}$ light/dark cycles at Beijing Friendship Hospital. All procedures were performed in accordance with the guidelines of the Institutional Animal Care and Ethics Committee at Beijing Friendship Hospital.

Conversion of DNT cells in vitro and adoptive transfer. The conversion of DNT cells in vitro was performed as previously described ${ }^{15,16}$. Briefly, mature dendritic cells (mDCs) were harvested from lipopolysaccharide-stimulated bone marrow cells derived from C57BL/6J mice and separated according to CD86positive selection. C57BL/6J or $\mathrm{C} 57 \mathrm{BL} / 6 \mathrm{~J}-\mathrm{GFP} \mathrm{CD}^{+} \mathrm{T}$ cells were incubated with C57BL/6J mDCs, $50 \mathrm{ng} / \mathrm{ml} \mathrm{rmIL-2} \mathrm{(PeproTech,} \mathrm{USA)} \mathrm{and} 1 \mu \mathrm{g} / \mathrm{ml} \mathrm{OVA}_{329-339}$ peptide, $\mathrm{MOG}_{35-55}$ peptide (Sigma-Aldrich) or HDM extract (Greer) for 7 days. $\mathrm{CD} 3^{+} \mathrm{CD} 4^{-} \mathrm{CD} 8^{-} \mathrm{NK} 1.1^{-}$DN cells were sorted using a FACSArialI sorter (BD Biosciences, USA).

Asthma model and DNT cell treatment. Six- to eight-week-old male C57BL/6J mice were sensitized by i.p. injections of $20 \mu \mathrm{g}$ OVA (Sigma-Aldrich) in $50 \mu \mathrm{l}$ Imject $^{\text {th }}$ alum adjuvant (Thermo Fisher Scientific) in a total volume of $100 \mu \mathrm{l}$ on days 0 and 14. The control mice received alum adjuvant (PBS) only. Beginning on day 28 after the injections, the mice were exposed to aerosolized 1\% OVA (in $0.85 \% \mathrm{NaCl}$ solution) for $30 \mathrm{~min} /$ day for 3 consecutive days. On day 28 , the ex vivo-converted OVA-primed DNT cells $\left(2 \times 10^{6}\right)$ were transferred to the mice by tail vein injection after the first inhalation of 1\% OVA. In the HDM-induced allergic asthma model, 8 -week-old female BALB/c mice were sensitized by the i.p. injection of $100 \mu \mathrm{g}$ HDM extract (Greer) in $50 \mu \mathrm{l} \mathrm{Imject}{ }^{\mathrm{TM}}$ alum adjuvant. The sensitized mice were administered (i.n.) $25 \mu \mathrm{g}$ of HDM extract intranasally daily for 5 days starting at day 7. Ex vivo-converted HDM-primed DNT cells $\left(2 \times 10^{6}\right)$ were transferred into mice by tail vein injection after the first i.n. challenge.

Measurement of airway hyperreactivity to methacholine. $24 \mathrm{~h}$ after the last OVA aerosol challenge, airway hyperresponsiveness to methacholine was determined using noninvasive unrestrained whole body plethysmography (EMKA Technologies). The mice were placed in individual chambers and exposed to nebulized methacholine $(0,12.5,50$, or $100 \mathrm{mg} / \mathrm{ml}$ in PBS, $0 \mathrm{mg} / \mathrm{ml}$ as baseline) for $2 \mathrm{~min}$ followed by a $1 \mathrm{~min}$ rest. The enhanced pause (Penh) was then measured for $3 \mathrm{~min}$. The average Penh value were expressed for each methacholine concentration in comparison with the baseline Penh values. 
Tissue processing. The tracheas were cannulated and washed twice with $1 \mathrm{ml}$ of PBS before isolating the lungs. The lungs, lymph nodes (mesenteric, inguinal, axillary and mediastinum) and spleens were processed in RPMI 1640 medium. PBS was injected into the right ventricle to flush the circulating blood cells. The lungs were chopped into small pieces and digested with tissue digestion solution $(0.5 \mathrm{mg} / \mathrm{ml}$ collagenase IV plus $8 \mu \mathrm{g} / \mathrm{ml}$ DNase I in HBSS containing $5 \% \mathrm{FBS})$ for $20 \mathrm{~min}$ before passing the tissue through a $70-\mu \mathrm{m}$ cell strainer (BD Biosciences). Single cells were selected from the Aqua-stained (live) and $\mathrm{CD} 45^{+}$cell populations. RBC lysis buffer (Qiagen) was used to lyse the red blood cells. The bronchoalveolar lavage (BAL) fluid was stained with the Diff-Quik stain kit (Solarbio) according to the manufacturer's instructions.

Ig and cytokine detection. OVA-specific IgG and IgE levels were determined in the bronchoalveolar lavage (BAL) and serum samples collected at the end of the experiments. Briefly, for OVA-specific IgG and IgE, high-binding plates were coated overnight at $4{ }^{\circ} \mathrm{C}$ with $5 \mu \mathrm{g} / \mathrm{ml}$ OVA in carbonate buffer, blocked with $2 \%$ milk/PBS, and incubated with 1:1000-1:10,000 serum dilutions. The OVA-specific immunoglobulins were detected with an HRP-conjugated rat anti-mouse IgG antibody (Zsbio). The signal was developed by incubation with a standard TMB solution, and the optical density was read at $450 \mathrm{~nm}$. The total IgE level was quantified with a capture $\mathrm{mAb}$, biotin detection $\mathrm{mAb}$, and streptavidin-HRP from the Mouse IgE ELISA Ready-SET-Go! kit (eBioscience). Readings were also obtained to generate a standard curve prepared with purified mouse IgE.

IL-21 production was quantified in serum and BALF with a mouse IL-21 ELISA kit (eBioscience) according to the manufacturer's instructions. The standard curve was prepared with purified mouse IL-21. The concentrations of IL-4 and IL-5 were detected with the LEGENDplex Multi-Analyte Flow Assay Kit for Mouse Th Cytokine (BioLegend) according to the manufacturer's instructions. Analyses were performed with a FACSAriaII (BD Biosciences) and the LEGENDplex software (BioLegend).

Histological analysis. Serial sections were prepared from formalin-fixed, paraffinembedded lung tissue. The sections were stained with $\mathrm{H} \& \mathrm{E}$ or with periodic acidSchiff (PAS) reagent and scanned at $\times 20$ magnification with a DM 2500 (Leica Corporation). Images were prepared using LAS version 4.6.1 software (Leica Application Suite software). The mucus-secreting cells around the airways (mean in $10 \times 100 \mu \mathrm{m}$ fields) were detected using light microscopy. The number of mucusfilled (PAS+) cells $/ 100 \mu \mathrm{m}$ airway epithelium were enumerated in a blinded manner ${ }^{41}$. The inflammatory infiltrate analysis was scored as follows: absent was scored as 0,1 denoted 'rare infiltrate', 2 denoted 'mild' (only in a focal area), 3: denoted 'moderate' ( $<5$ cell lines deep) and 4 : denoted 'severe' ( $>5$ lines of cells deep $)^{42}$. All scores were enumerated in a blinded manner by 2 blinded independent investigators.

Flow cytometry. Anti-CD11b (ICRF44, dilution 1:200, Cat 101206), anti-CD11c (N418, dilution 1:200, Cat 117318), anti-I-A/I-E (M5/114.15.2, dilution 1:200, Cat 107614), anti-CD8a (53-6.7, dilution 1:500, Cat 100714), anti-CD103 (M290, dilution 1:200, Cat 557495), anti-CD40 (3/23, dilution 1:100, Cat 124611), antiCD80 (16-10A1, dilution 1:200, Cat 104707), anti-Siglec F (E50-2440, dilution 1:200, Cat 562680) and anti-Ly-6G (RB6-8C5, dilution 1:200, Cat 108408) antibodies were used to identify the DC and granulocyte populations. Anti-CD4 (GK1.5, dilution 1:500, Cat 100428), anti-B220 (RA3-6B2, dilution 1:400, Cat 103206), anti-CXCR5 (SPRCL5, dilution 1:100, Cat 551960), anti-Foxp3 (PCH101, dilution 1:100, Cat 45-4776-42), anti-GzmB (GB11, dilution 1:200, Cat 561142) and anti-PD-1 (29F.1A12, dilution 1:200, Cat 135216) antibodies and StreptavidinAPC (dilution 1:200, Cat 405207) were used to identify the T cell populations. Anti-IL4 (11B11, dilution 1:200, Cat 504103), anti-IL-13 (eBio13A, dilution 1:200, Cat 12-7133-41), anti-IL-17A (TC11-18H10, dilution 1:200, Cat 506903), anti-IL21 (4A9, dilution 1:200, Cat 131905) and anti-IFN- $\gamma$ (XMG1.2, dilution 1:200, Cat 505808) antibodies were used to identify cytokine-producing $\mathrm{CD} 4{ }^{+} \mathrm{T}$ cells. Zombie Aqua $^{\mathrm{TM}}$ Fixable Viability kits were used to exclude dead cells. The Zombie Aqua $^{\mathrm{TM}}$ Fixable Viability kits and fluorochrome-conjugated antibodies were purchased from BioLegend, eBioscience or BD Pharmingen.

For OVA tetramer staining, suspended cells were stained with $\mathrm{I}-\mathrm{A}^{\mathrm{b}} \mathrm{OVA}_{323-339}$ tetramer-PE (MBL) at $4^{\circ} \mathrm{C}$ for $1 \mathrm{~h}$. The surface marker antibodies were added without washing and incubated for $15 \mathrm{~min}$. The cells were washed once before flow cytometry detection. The data were collected using a FACSAriaII (BD Biosciences) and analyzed with FlowJo software (Tree Star).

DNT cell and DC coculture. OVA DNT cells were converted from $\mathrm{CD} 4^{+} \mathrm{T}$ cells as described above. $\mathrm{CD} 11 \mathrm{c}^{+} \mathrm{MHC}-\mathrm{II}^{+}$lung DCs were sorted from OVA-induced allergic asthma mice by a FACSAriaII sorter. A total of $4 \times 10^{4}$ DCs were cocultured with $2 \times 10^{4}$ OVA DNTs for 3 days. The proportion and costimulatory molecule expression of DCs were assessed by flow cytometry.

DiD labeling \& confocal microscopy. $\mathrm{CD} 11 \mathrm{C}^{+} \mathrm{MHC}-\mathrm{II}^{+}$lung DCs were sorted by flow cytometry. $5 \mu \mathrm{g} / \mathrm{mL}$ DiD dye (Thermo Fisher Scientific) was added to $1 \times 10^{6} /$ $\mathrm{mL}$ DCs suspended in serum-free RPMI 1640 medium. The DCs were incubated for $20 \mathrm{~min}$ at $37^{\circ} \mathrm{C}$ and washed twice with RPMI 1640 medium containing $10 \%$
FBS. To investigate the trogocytosis process directly, we cocultured $5 \times 10^{5} \mathrm{GFP}^{+}$ OVA DNTs and DiD-labeled DCs for $24 \mathrm{~h}$ at a ratio of 1:1 in a 24-well plate. For confocal microscopy, the antibodies used were rabbit anti-mouse Lag3 antibody (Abcam) and mouse-purified anti-mouse I- $\mathrm{A}^{\mathrm{b}}$ (Biolegend), and DAPI was used as a nuclear stain (Molecular Probes). Donkey anti-rabbit IgG Alexa Fluor 546 and donkey anti-mouse IgG Alexa Fluor 647 (Thermo Fisher Scientific) were used to detect the primary Abs. Confocal analysis was conducted using a confocal laser scanning microscope (FLUOVIEW FV1000, Olympus). The image data were acquired by FV10-ASW 4.2 microscopy software.

RNA extraction and real-time PCR. Total RNA was extracted with a RNeasy Micro Kit (Qiagen), and the CDNA was reverse transcribed with a Prime Script ${ }^{\oplus}$ RT reagent Kit (Takara). Real-time PCR was performed with the 7500 Fas Real-time System (Applied Biosystems) using SYBR Green Master Mix (Applied Biosystems). The primers used in this study are listed in Supplementary Table 1. The real-time PCR relative values were calculated with the comparative Ct method and were normalized against the expression of the housekeeping gene $\beta$-actin.

Statistics. The statistical analyses were performed with GraphPad Prism software (GraphPad Software Inc., USA), and the experimental data are presented as the mean \pm standard deviation (SD). One-way ANOVA with a Bonferroni or Tukey posttest was used for multiple comparisons; a 2-tailed, unpaired $t$-test was used for unmatched pairwise sample comparisons (SPSS 23). Significant differences are shown as ${ }^{*} P<0.05,{ }^{* *} P<0.01$, and ${ }^{* * *} P<0.001$.

Reporting summary. Further information on research design is available in the Nature Research Reporting Summary linked to this article.

\section{Data availability}

The data supporting the findings of this paper are available from the corresponding author upon reasonable request. The source data underlying Figs. $1 \mathrm{~b}-\mathrm{e}, 2 \mathrm{~b}, 3 \mathrm{a}-\mathrm{c}, 4 \mathrm{a}-\mathrm{j}$, $5 a-d, 6 a-j, 7 a-e, S 2, S 3, S 4 B-E$ and $S 5$ are provided as a source data file.

Received: 14 January 2019 Accepted: 28 August 2019

Published online: 18 September 2019

\section{References}

1. Pawankar, R. Allergic diseases and asthma: a global public health concern and a call to action. World Allergy Organ. J. 7, 12 (2014).

2. Papi, A., Brightling, C., Pedersen, S. E. \& Reddel, H. K. Asthma. Lancet 391, 783-800 (2018).

3. Cooper, V. et al. Patient-reported side effects, concerns and adherence to corticosteroid treatment for asthma, and comparison with physician estimates of side-effect prevalence: a UK-wide, cross-sectional study. NPJ Prim. Care Respir. Med 25, 15026 (2015).

4. Fahy, J. V. Type 2 inflammation in asthma-present in most, absent in many. Nat. Rev. Immunol. 15, 57-65 (2015).

5. Foster, P. S. et al. Modeling TH 2 responses and airway inflammation to understand fundamental mechanisms regulating the pathogenesis of asthma. Immunological Rev. 278, 20-40 (2017).

6. Lambrecht, B. N. \& Hammad, H. Lung dendritic cells in respiratory viral infection and asthma: from protection to immunopathology. Annu. Rev. Immunol. 30, 243-270 (2012).

7. Kubo, M. Innate and adaptive type 2 immunity in lung allergic inflammation Immunological Rev. 278, 162-172 (2017).

8. Ballesteros-Tato, A. et al. T Follicular helper cell plasticity shapes pathogenic $\mathrm{T}$ helper 2 cell-mediated immunity to inhaled house dust mite. Immunity $\mathbf{4 4}$, 259-273 (2016)

9. Noble, A. \& Zhao, J. Follicular helper T cells are responsible for IgE responses to Der $\mathrm{p} 1$ following house dust mite sensitization in mice. Clin. Exp. Allergy 46, 1075-1082 (2016).

10. Matsuda, M. et al. Regulation of allergic airway inflammation by adoptive transfer of CD4(+) T cells preferentially producing IL-10. Eur. J. Pharmacol. 812, 38-47 (2017).

11. Zhang, Z. X., Yang, L., Young, K. J., DuTemple, B. \& Zhang, L. Identification of a previously unknown antigen-specific regulatory $\mathrm{T}$ cell and its mechanism of suppression. Nat. Med. 6, 782-789 (2000).

12. Fischer, K. et al. Isolation and characterization of human antigen-specific TCR alpha beta $+\mathrm{CD} 4(-) \mathrm{CD} 8$ - double-negative regulatory T cells. Blood 105 , $2828-2835$ (2005)

13. Juvet, S. C. \& Zhang, L. Double negative regulatory T cells in transplantation and autoimmunity: recent progress and future directions. J. Mol. Cell Biol. 4, 48-58 (2012). 
14. Hillhouse, E. E. \& Lesage, S. A comprehensive review of the phenotype and function of antigepn-specific immunoregulatory double negative $\mathrm{T}$ cells. $J$. Autoimmun. 40, 58-65 (2013).

15. Zhang, D. et al. New differentiation pathway for double-negative regulatory $\mathrm{T}$ cells that regulates the magnitude of immune responses. Blood 109, 4071-4079 (2007).

16. Zhang, D. et al. Adoptive cell therapy using antigen-specific CD4(-)CD8(-)T regulatory cells to prevent autoimmune diabetes and promote islet allograft survival in NOD mice. Diabetologia 54, 2082-2092 (2011).

17. Liu, T. et al. Combination of double negative $\mathrm{T}$ cells and anti-thymocyte serum reverses type 1 diabetes in NOD mice. J. Transl. Med 14, 57 (2016).

18. Coquet, J. M. et al. Interleukin-21-Producing CD4(+) T Cells Promote Type 2 Immunity to House Dust Mites. Immunity 43, 318-330 (2015)

19. Krishnaswamy, J. K. et al. Migratory CD11b(+) conventional dendritic cells induce $\mathrm{T}$ follicular helper cell-dependent antibody responses. Sci. Immunol. 2, pii: eaam9169 (2017)

20. Huard, B., Prigent, P., Tournier, M., Bruniquel, D. \& Triebel, F. CD4/major histocompatibility complex class II interaction analyzed with CD4- and lymphocyte activation gene-3 (LAG-3)-Ig fusion proteins. Eur. J. Immunol. 25, 2718-2721 (1995).

21. Zhao, X. et al. A novel differentiation pathway from CD4(+) T cells to CD4(-) $\mathrm{T}$ cells for maintaining immune system homeostasis. Cell Death Dis. 7, e2193 (2016).

22. Maruhashi, T. et al. LAG-3 inhibits the activation of CD4(+) T cells that recognize stable pMHCII through its conformation-dependent recognition of pMHCII. Nat immunol. https://doi.org/10.1038/s41590-018-0217-9 (2018).

23. Ford McIntyre, M. S., Young, K. J., Gao, J., Joe, B. \& Zhang, L. Cutting edge: in vivo trogocytosis as a mechanism of double negative regulatory $\mathrm{T}$ cellmediated antigen-specific suppression. J. Immunol. 181, 2271-2275 (2008).

24. Shalek, A. K. et al. Vertical silicon nanowires as a universal platform for delivering biomolecules into living cells. Proc. Natl Acad. Sci. USA 107, 1870-1875 (2010).

25. Vinuesa, C. G., Linterman, M. A., Yu, D. \& MacLennan, I. C. Follicular Helper T Cells. Annu. Rev. Immunol. 34, 335-368 (2016).

26. Gong, F. et al. Circulating $\mathrm{CXCR} 5^{+} \mathrm{CD} 4{ }^{+} \mathrm{T}$ cells participate in the $\operatorname{IgE}$ accumulation in allergic asthma.Immunol. Lett. 197, 9-14 (2018).

27. Janss, T. et al. Interferon response factor-3 promotes the pro-Th2 activity of mouse lung $\mathrm{CD} 11 \mathrm{~b}+$ conventional dendritic cells in response to house dust mite allergens. Eur. J. immunol. 46, 2614-2628 (2016).

28. Nobs, S. P. et al. PPARgamma in dendritic cells and T cells drives pathogenic type-2 effector responses in lung inflammation. J. Exp. Med. 214, 3015-3035 (2017).

29. Conejero, L. et al. Lung CD103+ dendritic cells restrain allergic airway inflammation through IL-12 production. JCI insight 2, pii: 90420 (2017).

30. Sinclair, C. et al. mTOR regulates metabolic adaptation of APCs in the lung and controls the outcome of allergic inflammation. Science 357, 1014-1021 (2017).

31. Huang, J. F. et al. TCR-Mediated internalization of peptide-MHC complexes acquired by T cells. Science 286, 952-954 (1999).

32. Hwang, I. et al. T cells can use either $\mathrm{T}$ cell receptor or CD28 receptors to absorb and internalize cell surface molecules derived from antigen-presenting cells. J. Exp. Med. 191, 1137-1148 (2000).

33. Ahmed, R. K. et al. TCR+CD4-CD8- T cells in antigen-specific MHC class Irestricted $\mathrm{T}$-cell responses after allogeneic hematopoietic stem cell transplantation. J. Immunother. 37, 416-425 (2014).

34. Mou, Z. et al. MHC class II restricted innate-like double negative T cells contribute to optimal primary and secondary immunity to Leishmania major. PLoS Pathog. 10, e1004396 (2014).

35. Triebel, F. et al. LAG-3, a novel lymphocyte activation gene closely related to CD4. J. Exp. Med. 171, 1393-1405 (1990).

36. Nakayama, M. Antigen Presentation by MHC-Dressed. Cells Front. Immunol. 5, 672 (2014).
37. Gagliani, N. et al. Coexpression of CD49b and LAG-3 identifies human and mouse T regulatory type 1 cells. Nat. Med. 19, 739-746 (2013).

38. Huang, C. T. et al. Role of LAG-3 in regulatory T cells. Immunity 21, 503-513 (2004).

39. Zhang, Q. et al. LAG3 limits regulatory $\mathrm{T}$ cell proliferation and function in autoimmune diabetes. Sci. Immunol. 2, pii: eaah4569 (2017).

40. Nguyen, Q. T. et al. IL-27 targets Foxp3+ Tregs to mediate antiinflammatory functions during experimental allergic airway inflammation. JCI insight 4, pii: 123216 (2019).

41. Al-Kouba, J. et al. Allergen-encoding bone marrow transfer inactivates allergic $\mathrm{T}$ cell responses, alleviating airway inflammation. JCI insight 2, pii: 85742 (2017).

42. Elsakkar, M. G., Sharaki, O. A., Abdallah, D. M., Mostafa, D. K. \& Shekondali, F. T. Adalimumab ameliorates OVA-induced airway inflammation in mice: Role of CD4(+) CD25(+) FOXP3(+) regulatory T-cells. Eur. J. Pharmacol. 786, 100-108 (2016).

\section{Acknowledgements}

This work was supported by grants from the National Natural Science Foundation of China (No. 81601388 and 81870399 ).

\section{Author contributions}

All listed authors participated meaningfully in the study, and they have reviewed and approved the submission of this manuscript. D.T. participated in performing the research, analyzing the data and writing the original draft of the article. L.Y., S.W., Y.Z., W.S., C.Z., H.J., Y.T., H.X., G.S., K.L., and Z.Z. participated in performing the research and collecting the data. D.Z. established the hypotheses, supervised the studies, analyzed the data and co-wrote the paper.

\section{Additional information}

Supplementary Information accompanies this paper at https://doi.org/10.1038/s41467 019-12243-0.

Competing interests: The authors declare no competing interests.

Reprints and permission information is available online at http://npg.nature.com/ reprintsandpermissions/

Peer review information Nature Communications thanks Nelly Frossard and Li Zhang for their contribution to the peer review of this work.

Publisher's note Springer Nature remains neutral with regard to jurisdictional claims in published maps and institutional affiliations.

Open Access This article is licensed under a Creative Commons Attribution 4.0 International License, which permits use, sharing, adaptation, distribution and reproduction in any medium or format, as long as you give appropriate credit to the original author(s) and the source, provide a link to the Creative Commons license, and indicate if changes were made. The images or other third party material in this article are included in the article's Creative Commons license, unless indicated otherwise in a credit line to the material. If material is not included in the article's Creative Commons license and your intended use is not permitted by statutory regulation or exceeds the permitted use, you will need to obtain permission directly from the copyright holder. To view a copy of this license, visit http://creativecommons.org/ licenses/by/4.0/

(C) The Author(s) 2019 